\title{
A Methyl Scan of the Pyrrolidinium Ring of Nicotine Reveals Significant Differences in Its Interactions with $\alpha 7$ and $\alpha 4 \beta 2$ Nicotinic Acetylcholine Receptors $\$$
}

\author{
Hong Xing, Kristin W. Andrud, ${ }^{1}$ Ferenc Soti, Anne Rouchaud, Stephan C. Jahn, Ziang Lu, \\ Yeh-Hyon Cho, Sophia Habibi, Patrick Corsino, Svetoslav Slavov, James R. Rocca, \\ Jon M. Lindstrom, Ron J. Lukas, and William R. Kem
}

Department of Pharmacology and Therapeutics (H.X., K.W.A., F.S., A.R., S.C.J., Z.L., Y.-H.C., S.H., P.C., W.R.K.) and AMRIS, McKnight Brain Institute (J.R.R.), College of Medicine, University of Florida, Gainesville, Florida; National Center for Toxicological Research, US Food and Drug Administration, Jefferson, Arkansas (S.S.); Department of Neuroscience, University of Pennsylvania, Philadelphia, Pennsylvania (J.M.L.); and Division of Neurobiology, Barrow Neurologic Institute, Phoenix, Arizona (R.J.L.)

Received November 2, 2019; accepted May 6, 2020

\section{ABSTRACT}

The two major nicotinic acetylcholine receptors (nAChRs) in the brain are the $\alpha 4 \beta 2$ and $\alpha 7$ subtypes. A "methyl scan" of the pyrrolidinium ring was used to detect differences in nicotine's interactions with these two receptors. Each methylnicotine was investigated using voltage-clamp and radioligand binding techniques. Methylation at each ring carbon elicited unique changes in nicotine's receptor interactions. Replacing the $1^{\prime}-N$-methyl with an ethyl group or adding a second $1^{\prime}-N$-methyl group significantly reduced interaction with $\alpha 4 \beta 2$ but not $\alpha 7$ receptors. The 2'-methylation uniquely enhanced binding and agonist potency at $\alpha 7$ receptors. Although $3^{\prime}$ - and 5'-trans-methylations were much better tolerated by $\alpha 7$ receptors than $\alpha 4 \beta 2$ receptors, 4 '-methylation decreased potency and efficacy at $\alpha 7$ receptors much more than at $\alpha 4 \beta 2$ receptors. Whereas cis- 5 '-methylnicotine lacked agonist activity and displayed a low affinity at both receptors, trans $-5^{\prime}$-methylnicotine retained considerable $\alpha 7$ receptor activity. Differences between the two 5'-methylated analogs of the potent pyridyl oxymethylene-bridged nicotine analog A84543 were consistent with what was found for the
5 -methylnicotines. Computer docking of the methylnicotines to the Lymnaea acetylcholine binding protein crystal structure containing two persistent waters predicted most of the changes in receptor affinity that were observed with methylation, particularly the lower affinities of the cis-methylnicotines. The much smaller effects of $1^{\prime}-, 3^{\prime}$-, and $5^{\prime}$-methylations and the greater effects of $2^{\prime}$ - and $4^{\prime}$-methylations on nicotine $\alpha 7$ nAChR interaction might be exploited for the design of new drugs based on the nicotine scaffold.

\section{SIGNIFICANCE STATEMENT}

Using a comprehensive "methyl scan" approach, we show that the orthosteric binding sites for acetylcholine and nicotine in the two major brain nicotinic acetylcholine receptors interact differently with the pyrrolidinium ring of nicotine, and we suggest reasons for the higher affinity of nicotine for the heteromeric receptor. Potential sites for nicotine structure modification were identified that may be useful in the design of new drugs targeting these receptors.

\section{Introduction}

Nicotine activates a variety of ligand-gated acetylcholine receptors ( $\mathrm{nAChRs}$ ) that play important signaling roles in neuronal and some non-neuronal cells, and it has a number of potentially therapeutic effects. However, it is one of the most

The views presented in this article are those of the authors and do not necessarily reflect those of the US Food and Drug Administration. No official endorsement is intended nor should be inferred.

This research was funded by the Florida Biomedical Research Program [Grant BM013] to W.R.K. and the National Institute of Mental Health [Grant MH-061412] to R.F.

${ }^{1}$ Current affiliation: Department of Biological Sciences, University of Denver, Denver, Colorado.

https://doi.org/10.1124/mol.119.118786.

S This article has supplemental material available at molpharm. aspetjournals.org. addictive drugs when self-administered as a tobacco product. Nicotine is also widely used as a useful smoking-cessation drug in nonsmoked formulations (Prochaska and Benowitz, 2016). Several nicotine analogs have already been tested as potential treatments for neurodegenerative and psychiatric disorders.

Vertebrate $\mathrm{nAChRs}$ are cation permeant ion channels composed of five homologous subunits. Molecular biologic investigations have revealed genes for 17 different subunits, so a large number of subunit combinations are theoretically possible, and $>15$ pentameric subunit combinations have already been identified in mammalian tissues ( $\mathrm{Wu}$ and Lukas, 2011). At least two $\alpha$ subunits occur in each $\mathrm{nAChR}$ pentamer. Agonist binding sites are located within a groove 


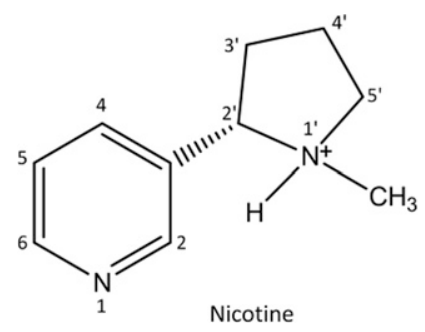

between the $\mathrm{N}$-terminal extracellular domains of an $\alpha$ subunit and an adjacent subunit. The $\alpha 7$ and $\alpha 4 \beta 2 \mathrm{nAChRs}$ are the most numerous and widely distributed receptor subtypes in the brain and have been demonstrated to participate in cognitive function. The $\alpha 7 \mathrm{nAChRs}$ are mainly homomeric complexes containing five $\alpha 7$ monomers, although small concentrations of $\alpha 7 \beta 2 \mathrm{nAChRs}$ also occur in the brain (Moretti et al., 2014; Nielsen et al., 2018). All the other nAChRs contain two or three non- $\alpha$ subunits. Significant decreases in the concentrations of these two receptors have been found in the postmortem brains of patients with Alzheimer disease and Parkinson disease (Burghaus et al., 2003). In many patients with schizophrenia, the $\alpha 7$ receptor is expressed at lower than normal levels, and this is thought to contribute to deficient sensory gating and cognition (Martin et al., 2004). There is considerable pharmaceutical interest in developing selective nicotinic agonists and allosteric modulators that target either $\alpha 7$ or $\alpha 4 \beta 2 \mathrm{nAChRs}$ for treating cognitive deficits in neurodegenerative diseases. Partial agonists for $\alpha 4 \beta 2$ receptors like varenicline and cytisine are widely used as smoking-cessation drugs. In addition, $\alpha 7$ nAChRs occurring in macrophages (and their brain counterparts, microglia), lymphocytes, keratinocytes, lung epithelium, and certain cancer cells modulate a variety of signaling pathways and have become attractive therapeutic targets (Bertrand et al., 2015; Bouzat et al., 2018).

Despite the widespread use of nicotine as an experimental $\mathrm{nAChR}$ probe and lead compound for the design of new drugs, the molecular basis for its preferential interactions with certain $\mathrm{nAChRs}$ is still poorly understood. Initial chemical modification and mutagenesis studies led to the identification of key aromatic amino acid side chains and peptide bonds constituting ACh binding sites (Changeux, 2012). A combination of cation- $\pi$, electrostatic, hydrogen, and van der Waals bonding forces are involved in ligand (agonist and competitive antagonist) recognition (Cashin et al., 2005; Xiu et al., 2009; Puskar et al., 2011). High-resolution crystal structures of several homologous acetylcholine binding proteins (AChBPs) and their analogs mutated to better resemble the $\alpha 7$ orthosteric binding site have been available for some time (Celie et al., 2004; Li et al., 2011). Crystal structures of the extracellular portions of the adult skeletal muscle $\alpha 1$ subunit and the $\alpha 10$ subunit binding $\alpha$-bungarotoxin ( $\alpha$-BTX) have been reported (Dellisanti et al., 2007; Zouridakis et al., 2014). Recently, a crystal structure of the nearly whole $\alpha 4_{2} \beta 2_{3}$ nAChR became available (Morales-Perez et al., 2016). These structures have been very useful for developing homology models of various $\mathrm{nAChRs}$ and have enabled ligand docking studies.

In view of the multiplicity of $\mathrm{nAChRs}$ and the need to minimize the adverse effects of nicotinic drugs on unintended $\mathrm{nAChRs}$, it is desirable to identify structural differences between their orthosteric binding sites to enable the design of subtype-selective drugs. In the present study we employ a "methyl scan" (Black et al., 1972) approach to assess the consequences of single methyl substitutions for each of the eight hydrogens located on the pyrrolidinium ring of nicotine. Methyl substitution was selected because of its relatively minimal effect (a 16\% increase) in the mass of the pyrrolidinium moiety. The methyl group, like the four methylene groups in this ring, does not appreciably affect the lipophilic nature of the ring, introduces no new hydrogen-bonding atoms, and does not diminish ionization of the pyrrolidinium nitrogen, which has been shown to be essential for efficient nAChR binding by this compound (Barlow and Hamilton, 1962; Jeng and Cohen, 1980).

The actions of a few alkylated nicotines on isolated tissues and organs have been reported (Glassco et al., 1994; Dukat et al., 1996). Two laboratories reported extensive rat brain nAChR (later shown to be largely $\alpha 42 \beta$ ) binding data on the effect of individual methyl substitutions at four of the eight hydrogens on the pyrrolidinium ring (Lin et al., 1994; Kim et al., 1996; Wang et al., 1998). In this paper, we report a comprehensive functional and radioligand binding analysis of all the possible chiral nicotine analogs generated by methyl replacement of each $\mathrm{H}$ atom attached to the pyrrolidinium ring of (S)-nicotine for $\alpha 7$ as well as $\alpha 4 \beta 2 \mathrm{nAChRs.} \mathrm{In} \mathrm{addition,}$ we evaluate the effect of increasing the size of the pre-existing $1^{\prime}-N$-methyl group. To test the generality of our results with nicotine, we extended part of our methyl scan to a highly potent nicotine analog, A84543, whose two nicotine-like rings are connected through an oxymethylene bridge that preserves the chirality of the 2 '-pyrrolidinium ring (Abreo et al., 1996). Our results indicate that the pyrrolidinium moiety in these compounds has a similar binding mode in both $\mathrm{nAChR}$ binding sites but that the $\alpha 7$ site is less sensitive to most methyl substitutions.

\section{Materials and Methods}

Nicotine Analogs. Preparation of all known compounds followed methods already described in the literature [see Fig. 1 in Rouchaud and Kem (2012) for a summary of most methods we employed]. The compound ${ }^{1} \mathrm{H}$ and ${ }^{13} \mathrm{C}$ NMR spectral and mass spectrometric data of compounds whose syntheses were previously reported agreed with the published data. The chiral high pressure liquid chromatography conditions (Tang et al., 1998) and identifying (Testa and Jenner, 1973) the individual enantiomers from the racemic $22^{\prime}-, 3^{\prime}$-, and $5^{\prime}$ methylnicotines are provided in the Supplemental Data. Nicotine dihydrogen tartrate salt (MW 462) was obtained from Sigma-Aldrich (St. Louis, MO). 1'-Methylnicotinium iodide (MW 304) was purchased from Toronto Research Chemicals (Toronto, Canada), and its identity was checked by NMR spectroscopy. In this paper, the relative configurations (cis- or trans-) of the pyrrolidinium ring methyl substituents are always expressed with respect to the configuration 
of the pyridyl substituent. All alkylnicotines in Tables 1-5 have the same 2 '-(S)-pyrrolidinium ring configuration as in natural (S)-nicotine. Data for 3'-methyl and 5'-methyl-(R)-nicotines are presented in Table 6. Abbreviations: $\mathrm{Me}=$ methyl, Et=ethyl, $\mathrm{N}=$ nicotine, NorN=nornicotine.

Functional Experiments with Xenopus Oocytes. Frogs were purchased, maintained, and used under a University of Florida Institutional Animal Care and Use Committee approval for the Kem laboratory. Mature female frogs (Xenopus laevis) were anesthetized by immersion in a $1.5 \mathrm{~g} / \mathrm{l}$ solution of ethyl-3-aminobenzoate methanesulfonate (MP Biomedicals, Solon, OH) for 30 minutes. After the frog was completely unresponsive and immobile, it was decapitated with a guillotine, and its spinal cord was pithed before excision of the ovary, which was placed into calcium-free Barth saline [ $88 \mathrm{mM} \mathrm{NaCl}, 1 \mathrm{mM} \mathrm{KCl}, 2.38 \mathrm{mM}$ $\mathrm{NaHCO}_{3}, 0.82 \mathrm{mM} \mathrm{MgSO}$, $15 \mathrm{mM}$ HEPES, $0.012 \mathrm{mg} / \mathrm{ml}$ tetracycline hydrochloride (Sigma-Aldrich), pH $7.3 \pm 0.1$ ], opened with forceps, and washed three times with saline. Then, $50 \mathrm{ml}$ of $1.25 \mathrm{mg} / \mathrm{ml}$ type 1 collagenase (Worthington Biochemical Corporation, Freehold, NJ) solution dissolved in $\mathrm{Ca}^{2+}$-free Barth saline was added, and the oocytecontaining mass was gently shaken for 2 hours at room temperature. After washing three times with calcium-free saline and then three times with Barth saline containing $0.7 \mathrm{mM} \mathrm{Ca}^{2+}$, healthy stage 5 oocytes were transferred into dishes and incubated at $17^{\circ} \mathrm{C}$ overnight. Oocytes were routinely injected with $50 \mathrm{nl}$ of a solution containing $20 \mathrm{ng} \alpha 7$ mRNA (Peng et al., 1999) or $50 \mathrm{nl}$ of a mixture of $\alpha 4$ and $\beta 2$ mRNA (10 ng each) using a Drummond Nanoject II Auto-Injector. In some pilot experiments, oocytes were injected with 4:1 or 1:4 ratios (20 ng mRNA, total) of the two mRNAs to determine whether nicotine action under our experimental conditions was sensitive to subunit stoichiometry (Nelson et al., 2003). Finally, in one final set of experiments intended to investigate only the high agonist sensitivity $\alpha 4_{2} \beta 2_{3} \mathrm{nAChR}$, an equal weight ( $5 \mathrm{ng}$ ) of RNA for the human $\beta 2 \mathrm{AGS} \alpha 4$ concatemer was injected with $5 \mathrm{ng} \beta 2$ RNA in each oocyte, since this ratio has been shown to minimize expression of alternative stoichiometries of this receptor (Kuryatov et al., 2005). Injected oocytes were cultured in Barth's saline for $5-10$ days at $17^{\circ} \mathrm{C}$ with daily changes in the saline prior to recordings.

Individual oocytes were placed into a $20-\mu l$ oocyte perfusion chamber (model OPC-1 connected to a ValveLink8.2 system; Automate Scientific, Berkeley, CA) and perfused at a rate of $2.0 \mathrm{ml} / \mathrm{min}$ at room temperature with frog Ringer's solution $(115 \mathrm{mM} \mathrm{NaCl}, 2.5 \mathrm{mM}$ $\mathrm{KCl}, 10 \mathrm{mM}$ HEPES, $1.8 \mathrm{mM} \mathrm{CaCl}_{2}$, pH 7.3) containing $1 \mu \mathrm{M}$ atropine sulfate (Sigma-Aldrich) to block potential muscarinic responses. The two-microelectrode voltage-clamp technique was used to measure current responses at a constant holding potential ( $-60 \mathrm{mV}$ for $\alpha 7$ and $-50 \mathrm{mV}$ for $\alpha 4 \beta 2 \mathrm{nAChRs}$ ). The voltage-measuring microelectrode (filled with $3 \mathrm{M} \mathrm{KCl}$ solution) resistance was 0.5-3.0 $\mathrm{M} \Omega$, and the current-passing electrode (containing $250 \mathrm{mM} \mathrm{CsCl}$ and $100 \mu \mathrm{M}$ EGTA) resistance was $0.5-2.0 \mathrm{M} \Omega$. Membrane currents were recorded with an AxoClamp-2 (Axon Instruments, Union City, CA). Sampling rates were between 5 and $10 \mathrm{~Hz}$. Compounds were transiently applied (2 seconds for $\alpha 7$ and 5 seconds for $\alpha 4 \beta 2$ receptors) to avoid a cumulative desensitization. A rapid flow rate $(2.0 \mathrm{ml} / \mathrm{s})$ permitted complete replacement of the fluid bathing the oocyte at approximately $3 \times$ per second. Initially, each oocyte received two control applications of a nearmaximal stimulatory concentration of ACh (1 mM ACh for $\alpha 7$ and $100 \mu \mathrm{M}$ ACh for $\alpha 4 \beta 2$ receptors) to obtain a consistent response. ACh control applications alternated with test compound applications every 5 minutes. The peak current response for a given compound concentration was then normalized with respect to the mean current response, obtained by averaging the responses for the ACh applications before and after that test concentration. Clampfit 8.1 (Axon Instruments) was used for data acquisition, and Prism 3.0 (GraphPad, San Diego, CA) was used for analysis. The concentration-response curve for each compound was calculated by fitting the data using the following modified Hill equation:

$$
\text { Response } \mathrm{I}=\mathrm{I}_{\max }(\text { Agonist }) /\left[(\text { Agonist })^{n}+\left(\mathrm{EC}_{50}\right)^{n}\right] \text {, }
$$

where each response current I is normalized with respect to the abovementioned mean ACh control response; $I_{\max }$ denotes the maximal response current for the agonist, again relative to the ACh control response; and $n$ is the Hill slope. It has been demonstrated that $\alpha 7 \mathrm{nAChR}$ total current (net charge over time) concentration-response curves are shifted to lower concentrations relative to transient peak response-concentration curves (Papke and Thinschmidt, 1998). Thus, we measured net charge as well as peak current responses for each oocyte response. Total current over a 20 -second interval (including the 2 -second drug application period) was measured, and the net charge response was obtained after subtraction of baseline current for the same 20 -second period. Compound comparisons using the net charge method led to the same conclusions as for the peak current method (Table 1). The number of oocytes $(n)$ tested at each concentration was $\geq 4$ and is given in Fig. 2 . Efficacy $\left(I_{\max }\right)$ estimates by peak current and net charge methods and potency $\left(\mathrm{EC}_{50}\right)$ estimates are presented in Tables 1 and 3 as arithmetic means \pm one sample S.D. One-way ANOVA of $\log _{10}$-transformed compound $I_{\max }$ and $\mathrm{EC}_{50}$ data was used to compare all analogs with nicotine using Dunnett's multiple comparison post-test. Student's two-tailed $t$ test was used to assess statistical significance between mean $I_{\max }$ and $\mathrm{EC}_{50}$ estimates for the two enantiomers of a compound.

Radioligand Binding Experiments. Rat brain membrane radioligand binding experiments were carried out essentially as previously described (Kem et al., 2004). Frozen adult male SpragueDawley rat brains (Pel-Freeze Biologicals, Rogers, AZ), after thawing on ice and being sliced into smaller pieces, were homogenized with a $30-\mathrm{ml}$ Wheaton glass homogenizing tube and pestle in ice-cold binding saline (120 mM NaCl, $5 \mathrm{mM} \mathrm{KCl}, 2 \mathrm{mM} \mathrm{CaCl}_{2}, 1 \mathrm{mM} \mathrm{MgCl}_{2}$, $50 \mathrm{mM}$ Tris-HCl buffer, $\mathrm{pH}$ 7.4). After the homogenate was centrifuged at $14,600 \mathrm{~g}$ for 10 minutes, the resulting pellet was resuspended in fresh binding saline, homogenized, and centrifuged again, and the supernatant was discarded. A protein assay (BCA; Pierce, Rockford, IL) was then performed to obtain the protein concentration of the washed and pellet-resuspended membranes, which were stored at $-82^{\circ} \mathrm{C}$ before use. Each tube in the binding experiment received $100 \mu \mathrm{g}$ of rat brain membrane protein.

Washed membranes from cultured tsA201 cells expressing human $\alpha 4 \beta 2 \mathrm{nAChRs}$ were also used to assess the $\mathrm{nAChR}$ affinities of nicotine and most nicotine analogs. Although these cells are known to express both stoichiometries of this heteromeric receptor, nicotine binding curves in our study were well fitted, assuming a single population displaying the characteristics of the highest affinity $\left(\alpha 4_{2} \beta 2_{3}\right)$ form (Kuryatov et al., 2005). Cells at $80 \%-90 \%$ confluence were collected with a disposable cell scraper after removing the culturing media from the flask $\left(75 \mathrm{~cm}^{2}\right)$ and adding $6-10 \mathrm{ml}$ of ice-cold Tris binding saline. The dislodged cells were collected in centrifuge tubes and spun down at $7700 \mathrm{~g}$ for 8 minutes. The loose pellet was collected and homogenized as described above for rat brain membranes; after a protein assay, the washed membranes were stored at $-85^{\circ} \mathrm{C}$ before use. For tsA201 cell membranes, $50 \mu \mathrm{g}$ of protein per tube was used for radioligand binding experiments. SH-EP1 cells expressing human $\alpha 7 \mathrm{nAChRs}$ were similarly cultured, and their membranes $(100 \mu \mathrm{g}$ membrane protein per tube) were used in $\left[{ }^{125} \mathrm{I}\right] \alpha$-BTX displacement assays (Zhao et al., 2003).

Radioligands selective for each $\mathrm{nAChR}$ subtype were obtained from Perkin Elmer Life and Analytical Sciences (Boston, MA). Using conditions reported to optimally measure $\alpha 4 \beta 2 \mathrm{nAChR}$ affinity, 1.0 $\mathrm{nM}\left[{ }^{3} \mathrm{H}\right]$ cytisine $(34 \mathrm{Ci} / \mathrm{mmol})$ displacement experiments were performed at $4^{\circ} \mathrm{C}$ as previously reported by Pabreza et al. (1991). Measurements of $\alpha 7 \mathrm{nAChR}$ affinity were done by displacement of $\left[{ }^{125} \mathrm{I}\right] \alpha$-BTX (136 Ci/mmol) binding; the final test $\left[{ }^{125} \mathrm{I}\right] \alpha$-BTX concentration was $0.32 \mathrm{nM}$. These experiments required incubation for 3 hours at $37^{\circ} \mathrm{C}$ to assure equilibration. Membranes were suspended in binding saline containing $2 \mathrm{mg} / \mathrm{ml}$ bovine serum albumin (SigmaAldrich) to reduce nonspecific binding. In each experiment, 48 disposable glass culture tubes that were each (total volume $0.50 \mathrm{ml}$ ) containing equal concentrations of cell membranes and radioligand but different concentrations of the compound of interest were always incubated together. For each radioligand, nonspecific binding was 
measured in the presence of a final concentration of $1 \mathrm{mM}$ nicotine hydrogen tartrate (Sigma-Aldrich). After incubation, radioligand bound to membranes in each tube was rapidly collected by vacuum filtration using a 48-position Brandel cell harvester (Gaithersburg, $\mathrm{MD})$ and Whatman GF/C glass fiber filters that were presoaked in 0.5\% polyethylenimine (Sigma-Aldrich) for 45 minutes to reduce nonspecific binding. The radiolabeled membranes were rapidly washed three times with $3 \mathrm{ml}$ of ice-cold binding saline to remove the unbound radioligand. Filters containing $\left[{ }^{3} \mathrm{H}\right]$ cytisine bound membranes were collected in 20-ml scintillation tubes, suspended in $8 \mathrm{ml}$ of $30 \%$ Scintisafe (Fisher Scientific, Atlanta, GA) scintillation fluid, and then counted in a Beckman LS-6500 liquid scintillation counter after standing overnight. Filters containing $\left[{ }^{125} \mathrm{I}\right] \alpha$-BTX bound membranes were placed in 4-ml gamma vials and counted in a Beckman Instruments (Fullerton, CA) 5500B gamma counter.

Displacement assay binding data were analyzed using Prism software. The mean counts per minute for each compound concentration were obtained from four replicates; the data were fitted to a sigmoidal concentration-response curve for one-site binding, from which the Hill slope $(n)$ and $\mathrm{IC}_{50}$ were estimated as follows:

$$
\mathrm{Y}=\text { Bottom }+(\text { Top }- \text { Bottom }) /\left(1+10^{(\mathrm{X}-\log \text { IC50)n }}\right) .
$$

Top (of the curve) is the maximal specific binding plateau of radioligand, Bottom (of the curve) is the minimum specific binding plateau observed at high concentrations of the displacing ligand, and X = Log (Compound). The $\mathrm{K}_{\mathrm{d}}$ estimate for each radioligand and receptor, previously calculated from saturation binding experiments carried out using the same incubation conditions, was then used to calculate the equilibrium dissociation constant $\left(\mathrm{K}_{\mathrm{i}}\right)$ value of the displacing ligand from the Cheng-Prusoff equation: $\mathrm{K}_{\mathrm{i}}=\mathrm{IC}_{50} /\left[1+(\right.$ Radioligand $\left.) / \mathrm{K}_{\mathrm{d}}\right]$. For $\left[{ }^{3} \mathrm{H}\right]$ cytisine, the binding $\mathrm{K}_{\mathrm{d}}$ was $0.92 \mathrm{nM}$ for rat brain membranes and $0.48 \mathrm{nM}$ for human $\alpha 4 \beta 2$ receptors expressed in tsA201 cell membranes. For $\left[{ }^{125} \mathrm{I}\right] \alpha$-BTX, the $\mathrm{K}_{\mathrm{d}}$ was $0.67 \mathrm{nM}$ for rat brain membranes and $0.97 \mathrm{nM}$ for human $\alpha 7$ receptors expressed in SH-EP1 cell membranes. One-way ANOVA of $\log _{10}$-transformed compound mean $\mathrm{K}_{\mathrm{i}}$ values obtained from a number of individual experiments was used to compare analogs with nicotine using Dunnett's multiple comparison post-test. A Student's two-tailed $t$ test was used to assess statistical significance between the mean $\mathrm{K}_{\mathrm{i}}$ estimates for cis- and trans-enantiomers of a compound.

Computer Docking of Nicotine Analogs with nAChR Model Proteins. The protein crystal structures used for the in silico molecular docking were the Lymnaea AChBP, occupied by nicotine (Celie et al., 2004; Brookhaven Protein Data Bank accession code 1UW6), and a chimeric protein based on Aplysia californica AChBP containing binding site mutations to better resemble $\alpha 7 \mathrm{nAChR}$, which was occupied by epibatidine (Li et al., 2011, Brookhaven Protein Data Bank accession code 3SQ6). The molecular docking of all nicotine analogs was preceded by a two-step optimization process aimed at obtaining consistent starting geometries. The random walk algorithm implemented in HyperChem version 8.0 (HyperCube Inc., Gainesville, FL) was used to sample the potential energy surface to identify the lowest-energy conformation of each molecule. In total, 1000 conformations per molecule were generated by varying randomly all dihedral angles and using an acceptance energy cutoff of $6 \mathrm{kcal} / \mathrm{mol}$ above the best. All conformations with an energy difference of less than $0.05 \mathrm{kcal} / \mathrm{mol}$ were considered duplicates; hence, only one was retained. Conformations with potentially "bad" (distance between any two atoms of less than $0.5 \AA$ ) van der Waals contacts were discarded. The lowest-energy conformation was further subjected to a optimization in GAMESS (Schmidt et al., 1993) using an STO$3 \mathrm{G}$ basis set to represent the wave function in the Hartree-Fock approximation. Molecular surface calculations for each nicotine analog were made using MSROLL (Dock 6.5 Manual; University of California San Francisco, San Francisco, CA). Each molecular surface was used as input for the sphere-generating program SPHGEN (Dock 6.5; University of California San Francisco). A cluster of 77 spheres that overlapped with the ligand (a nicotine or epibatidine molecule in the appropriate crystal structure) was manually selected to be the point of interest in the subsequent docking calculations. SHOWBOX was used to construct a three-dimensional rectangle $6 \AA$ in any direction from the sphere cluster. CHIMERA (Pettersen et al., 2004) was used to prepare each protein structure and convert the file type to the necessary Mol2 format. The box file was used as input for the GRID program, which calculated the necessary information concerning the steric and electrostatic environment within the area of the box in the 1UW6 and 3SQ6 protein structures.

The nicotine analogs used as inputs for docking were energyminimized. DOCK6.5 (Allen et al., 2015) was then used to measure the predicted binding energies of the compounds within the binding pocket designated by the spheres. With ligand flexibility allowed, each compound was docked in a minimum of 20,000 orientations. Separate computations were done for docking to each of the following structures for the 1UW6 Lymnaea AChBP: 1) the water-free site, 2) the site containing persistent water A (Amiri et al., 2007) bound to the side chain oxygen on the complementary surface, 3 ) the site containing persistent water B binding to Tyr 192 (Amiri et al., 2007), and finally, 4 ) the site containing both of these waters. The fit of the lowest-energy docked structure of each docked nicotine compound relative to the 1UW6 nicotine-AChBP structure was estimated by calculating the root mean square deviation for the 11 ring atoms of nicotine (see Supplemental Table 2). The internet-available program Coote was used for these determinations. To allow comparison of the compound free energies of binding (calculated from the observed binding affinities of the compounds for the two human receptors) with the docking energies predicted for the two AChBPs, the predicted energies of the various analogs were first normalized with respect to the predicted nicotine docking energy. Then, the predicted docking energies of the compounds were normalized with respect to the experimental free energy changes (calculated from their $\mathrm{K}_{\mathrm{i}}$ values) associated with their binding to SH-EP1 cell-expressed human $\alpha 7$ receptors (Table 2). The experimental and predicted free energies of binding $(\Delta \mathrm{Gs})$ are presented in Table 5 .

\section{Results}

Concentration-Response Relationships for ACh, Nicotine, and the Methylnicotines. We measured the functional properties of each methylnicotine-namely, the $\mathrm{EC}_{50}$ (inversely related to potency) and $I_{\max }$ (maximal AChnormalized current)—using Xenopus oocytes expressing human $\alpha 7$ or $\alpha 4 \beta 2 \mathrm{nAChRs}$ to allow comparison of the compound with nicotine and its enantiomer. The concentration-current response curves of these two $\mathrm{nAChRs}$ for $\mathrm{ACh}$ and nicotine are shown in Supplemental Fig. 1. In addition, the same curve for nicotine, but without the S.E. bars, is included as a dashed line in each concentration-response curve in Fig. 2 to allow visual comparison with the nicotine analog curve. Because the $\alpha 7$ receptor is much less sensitive to ACh than the $\alpha \beta 42$ receptor, the standard calibrating agonist was $1000 \mu \mathrm{M}$ ACh, but for the $\alpha 4 \beta 2 \mathrm{nAChR}$, it was $100 \mu \mathrm{M}$ ACh. The two calibrating ACh concentrations were chosen to produce near-maximal responses that would not cause cumulative desensitization during the experiment.

Our concentration-response data for $\alpha 7$ receptors (Fig. 2; Table 1) includes both the more readily recorded peak current responses as well as currents integrated over the entire time of agonist response (net charge method). Both types of data were obtained from the same response. When administered by standard methods of oocyte perfusion, including ours, the $\alpha 7$ peak current response for an administered concentration of agonist does not reflect the maximum degree of receptor activation possible with that agonist concentration, because receptor desensitization is more rapid than the solution change: the peak current occurs before the desired concentration is 
$\alpha 7$

A

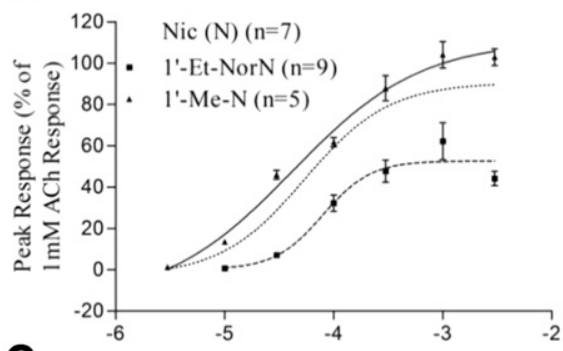

C

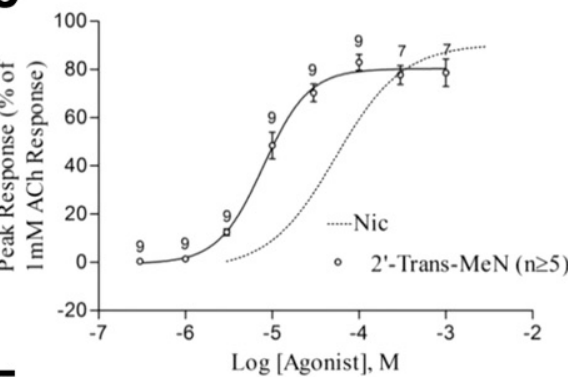

E

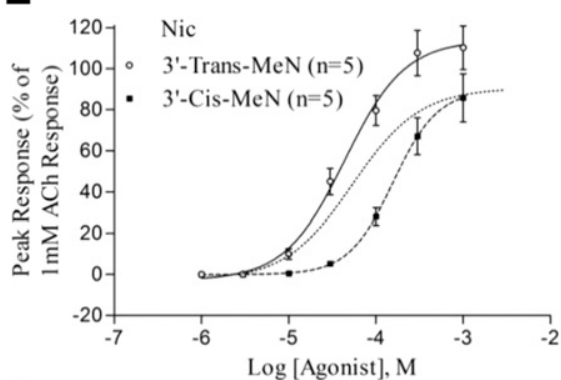

G

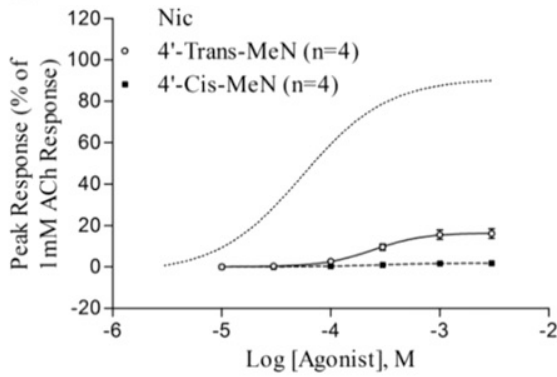

I

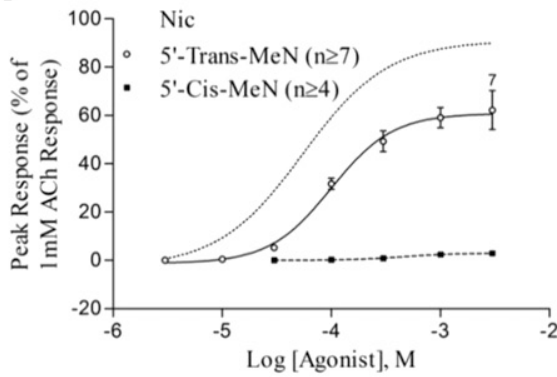

B

$\alpha 4 \beta 2$

1'-Me

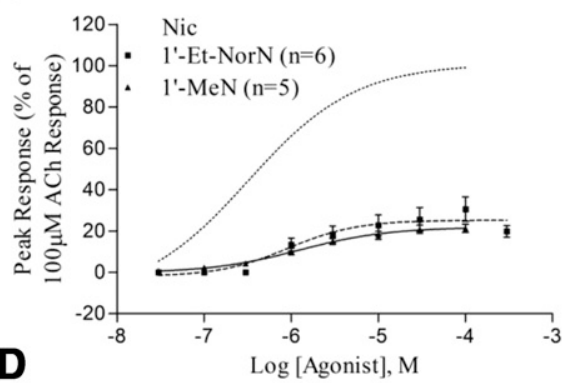

2'-Me

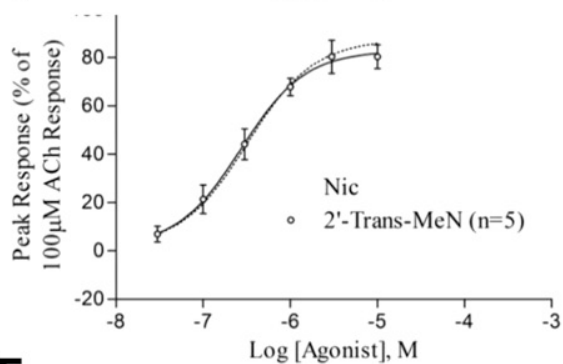

3'-Me

F

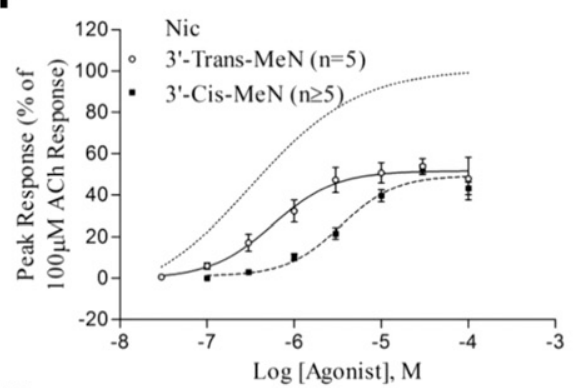

4'-Me

H

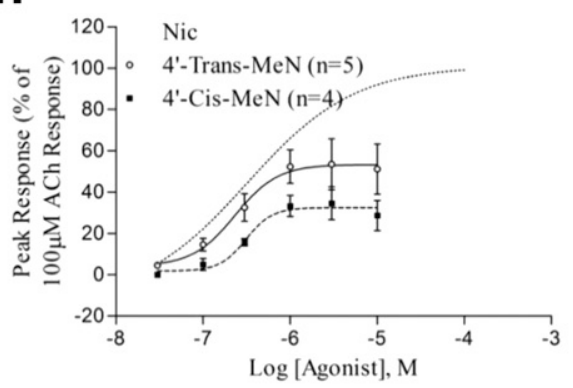

5'-Me

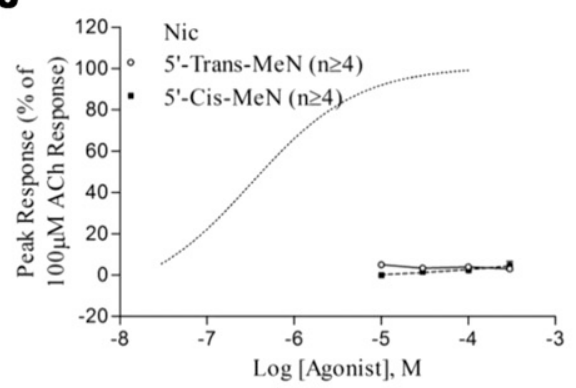

Fig. 2. Xenopus concentration-response curves for nicotine and the methylnicotines on human $\alpha 7$ (left, locants A, C, E, G and I) and $\alpha 4 \beta 2$ (right, locants $\mathrm{B}, \mathrm{D}, \mathrm{F}, \mathrm{H}$ and J) nAChRs. Peak current responses were recorded by the two-electrode voltage-clamp method described in Materials and Methods. Net charge $\mathrm{EC}_{50}$ and $I_{\max }$ values were also estimated from the same oocytes, and data obtained from both methods are summarized in Tables 1 and 3 . The error bars indicate \pm 1 S.E.M. $n=$ number of oocytes tested at a particular concentration. The complete concentration-response curves for nicotine and $\mathrm{ACh}$, including numbers of oocytes tested at each concentration, are found in Supplemental Figs. 1 and 2. Et, ethyl; Me, methyl; N, nicotine; NorN, nornicotine. 
TABLE 1

Functional properties of nicotine analogs acting on human $\alpha 7$ receptors expressed in Xenopus oocytes

Peak current and net charge estimates were obtained from each response. Mean estimates \pm one sample S.D. of the maximum current response $\left(I_{\max }\right)$ and potency $\left(\mathrm{EC}_{50}\right)$ are given.

\begin{tabular}{|c|c|c|c|c|c|c|c|}
\hline Compound & \multicolumn{3}{|c|}{$\mathrm{EC}_{50}(\mu \mathrm{M})$} & \multicolumn{2}{|c|}{$I_{\max }(\%$ of ACh Response) } & PC/NC Ratio & $n$ \\
\hline $\operatorname{Nic}(\mathrm{N})$ & $65.3 \pm 20$ & $21.2 \pm 7.4$ & 3.1 & $91.5 \pm 10$ & $85.4 \pm 20$ & 1.1 & 7 \\
\hline $1^{\prime}-\mathrm{MeN}$ & $51.4 \pm 11$ & $16.7 \pm 4.5$ & 3.1 & $109 \pm 11$ & $90.3 \pm 9.6$ & 1.2 & 5 \\
\hline $1^{\prime}$-EtNorN & $85.2 \pm 22$ & $30.7 \pm 12$ & 2.8 & $54.1 \pm 15^{* * *}$ & $55.9 \pm 10$ & 1.0 & 9 \\
\hline $2^{\prime}-\mathrm{MeN}$ & $9.65 \pm 4.0 * * *$ & $3.15 \pm 0.70^{* * *}$ & 3.1 & $82.4 \pm 6.9$ & $72.0 \pm 7.2$ & 1.1 & 5 \\
\hline $3^{\prime}-C i s-\mathrm{MeN}$ & $171 \pm 45^{*, \text { ttt }}$ & $68.1 \pm 42 *$ & 2.5 & $92.5 \pm 29$ & $62.6 \pm 8.5$ & 1.5 & 5 \\
\hline $4^{\prime}-$ Trans $-\mathrm{MeN}$ & $246 \pm 58^{* * *}$ & $113 \pm 32^{* * *}$ & 2.2 & $16.4 \pm 4.6^{* * *}$ & $27.3 \pm 4.6^{* * *}$ & 0.60 & 4 \\
\hline $4^{\prime}-$ Cis-MeN & $277 \pm 32^{* * *}$ & $186 \pm 120^{* *}$ & 1.5 & $1.81 \pm 0.80^{* * *}$ & $8.08 \pm 5.6^{* * *}$ & 0.20 & 4 \\
\hline 5'-Trans-MeN & $134 \pm 53^{*}$ & $39.3 \pm 15$ & 3.4 & $67.4 \pm 13$ & $54.8 \pm 6.6^{*}$ & 1.2 & 7 \\
\hline $5^{\prime}-\mathrm{Cis}-\mathrm{MeN}$ & $1010 \pm 860^{* * *, t t}$ & $479 \pm 110^{* * *, \mathrm{ttt}}$ & 2.1 & $4.42 \pm 2.0^{* * *, \text {,tt }}$ & $14.8 \pm 7.2^{* * *, \text {,tt }}$ & 0.3 & 4 \\
\hline
\end{tabular}

$n$, the number of oocytes used.

${ }^{*} P<0.05, * * P<0.01, * * * P<0.001$, comparison with nicotine. (These $P$ values were obtained from one-way ANOVA of log-transformed data with Dunnett's multiple comparison post-test.)

${ }^{t} P<0.05,{ }^{\text {tt}} P<0.01,{ }^{\text {"tt}} P<0.001$, comparison of $c$ is- and trans-enantiomers; these $P$ values were obtained from a two-tailed $t$ test and, thus, are not corrected for multiple comparisons. Et, ethyl; Me, methyl; N, nicotine; NorN, nornicotine.

reached at the oocyte membrane (Papke and Thinschmidt, 1998). Nevertheless, the peak current response should allow us to quantitatively compare the $\alpha 7$ response of a methylated nicotine relative to that of its enantiomer or nicotine, since the diffusion limited rates of equilibration of these compounds with the receptor should be nearly the same. In support of this assumption, net charge responses obtained from the agonist pulses yielded the same conclusions as for the peak current responses, except that the net charge $(\mathrm{NC})$ potency $\left(\mathrm{EC}_{50}\right)$ estimates were 2- to 3 -fold smaller than the Peak Current measured $\left(\mathrm{EC}_{50}\right)$ estimates in Table 1$)$.

Another consideration in the interpretation of the Xenopus oocyte functional data obtained with $\alpha 4 \beta 2 \mathrm{nAChRs}$ is related to their subunit stoichiometry. Our functional measurements of the methylnicotine effects were nearly complete when the coexpression of $\alpha 4 \beta 2 \mathrm{nAChRs}$ with different stoichiometries and pharmacological properties was shown to be of general occurrence (Moroni et al., 2006). The $\alpha 4_{3} \beta 2_{2}$ receptor with low sensitivity to AChandnicotine was reported to have a nicotine $\mathrm{EC}_{50}$ that is $\sim 50 \times$ higher than for the high-sensitivity $\alpha 4_{2} \beta 4_{3}$ receptor (Tavares et al., 2012). In our Xenopus oocyte experiments we routinely injected equal amounts of the two mRNAs. The nicotine concentration-response curve (Supplemental Fig. 1) that we obtained for $\alpha 4 \beta 2 \mathrm{nAChRs}$ was well fitted with Prism, assuming a single population of $\alpha 4 \beta 2 \mathrm{nAChRs}$. When the $\alpha 4 \beta 2$ mRNA ratio was either $4: 1$ or $1: 4$, we still obtained $\mathrm{EC}_{50}$ values for nicotine that were almost the same as when the mRNA ratio was 1:1 (results not shown). The $I_{\max }$ value of nicotine obtained with the 1:1 mRNA-injected oocytes was nearly identical with that of the $100 \mu \mathrm{M}$ ACh response,

TABLE 2

Nicotine analog binding to mammalian $\alpha 7 \mathrm{nAChRs}$ as measured by displacement of $\left[{ }^{125} \mathrm{I}\right] \alpha$-BTX-specific binding Mean $\mathrm{K}_{\mathrm{i}}$ estimates \pm one sample S.D. are given

\begin{tabular}{|c|c|c|c|c|c|c|}
\hline \multirow{2}{*}{ Compound } & \multicolumn{3}{|c|}{ Rat Brain Receptor } & \multicolumn{3}{|c|}{ Human Receptor (SH-EP1 Cell) } \\
\hline & $\mathrm{K}_{\mathrm{i}}(\mathrm{nM})$ & -Hill Slope & $n$ & $\mathrm{~K}_{\mathrm{i}}(\mathrm{nM})$ & -Hill Slope & $n$ \\
\hline $\operatorname{Nic}(\mathrm{N})$ & $808 \pm 85$ & 3.0 & 6 & $551 \pm 140$ & 1.1 & 5 \\
\hline $1^{\prime}-\mathrm{MeN}$ & $817 \pm 74$ & 2.5 & 3 & $917 \pm 200^{* * *}$ & 1.5 & 4 \\
\hline $1^{\prime}$-EtNorN & $2620 \pm 340^{* * *}$ & 2.3 & 4 & $2370 \pm 32^{* * *}$ & 1.2 & 4 \\
\hline $2^{\prime}-\mathrm{MeN}$ & $181 \pm 34^{* * *}$ & 2.9 & 7 & $144 \pm 24^{* * *}$ & 1.2 & 4 \\
\hline $3^{\prime}$-Trans-MeN & $752 \pm 120$ & 2.4 & 4 & $756 \pm 54^{*}$ & 1.2 & 4 \\
\hline 3'-Cis-MeN & $3120 \pm 500^{* * *, \text {,tt }}$ & 3.1 & 4 & $4780 \pm 12^{* * *, \text { ttt }}$ & 1.0 & 3 \\
\hline $4^{\prime}-$ Trans-MeN & $3910 \pm 30^{* * *}$ & 2.4 & 4 & $6850 \pm 630^{* * *}$ & 1.5 & 5 \\
\hline $4^{\prime}-\mathrm{Cis}-\mathrm{MeN}$ & $2930 \pm 58^{* * *, \text {,tt }}$ & 2.4 & 4 & $3300 \pm 16^{* * *, \text {,tt }}$ & 1.3 & 2 \\
\hline $5^{\prime}$-Trans-MeN & $2130 \pm 76^{* * *}$ & 1.5 & 3 & $1970 \pm 420^{* * *}$ & 1.1 & 4 \\
\hline $5^{\prime}$-Cis-MeN & $34,800 \pm 2600 * * *$, ,tt & 2.0 & 4 & $22,500 \pm 2600 * * *$, ttt & 1.1 & 4 \\
\hline
\end{tabular}

$n=$ the number of experiments.

${ }^{*} P<0.05,{ }^{* *} P<0.01,{ }^{* * *} P<0.001$, comparison with nicotine. (These $P$ values were obtained from one-way ANOVA of log-transformed data with Dunnett's multiple comparison post-test.)

${ }^{\mathrm{t}} P<0.05$, " $P<0.01$, " $P<0.001$, comparison of cis- and trans-enantiomers; these $P$ values were obtained from a two-tailed $t$ test and, thus, are not corrected for multiple comparisons. Et, ethyl; Me, methyl; N, nicotine; NorN, nornicotine. 
TABLE 3

Functional properties of nicotine analogs acting on human $\alpha 4 \beta 2$ receptors expressed in Xenopus oocytes

Mean estimates \pm one sample S.D. are given

\begin{tabular}{|c|c|c|c|}
\hline Compound & $\mathrm{EC}_{50}(\mu \mathrm{M})$ & $I_{\max }(\%$ ACh Response $)$ & $n$ \\
\hline $\mathrm{Nic}(\mathrm{N})$ & $0.430 \pm 0.33$ & $93.8 \pm 14$ & 11 \\
\hline $1^{\prime}$-Et-NorN & $3.65 \pm 2.1^{* * *}$ & $26.8 \pm 10^{* * *}$ & 6 \\
\hline $1^{\prime}-\mathrm{MeN}$ & $1.38 \pm 0.45^{* * *}$ & $22.5 \pm 5.4^{* * *}$ & 5 \\
\hline $2^{\prime}-\mathrm{MeN}$ & $0.738 \pm 0.089$ & $83.4 \pm 14$ & 5 \\
\hline $3^{\prime}-$ Trans-MeN & $0.74 \pm 0.42$ & $52.9 \pm 14^{* * *}$ & 5 \\
\hline $3^{\prime}-$ Cis-MeN & $3.83 \pm 1.2^{* * * *, \text {,tt }}$ & $51.4 \pm 5.4^{* * *}$ & 5 \\
\hline $4^{\prime}-$ Trans-MeN & $0.254 \pm 0.04$ & $55.7 \pm 27^{* * *}$ & 5 \\
\hline $4^{\prime}-C i s-\mathrm{MeN}$ & $0.285 \pm 0.14$ & $32.7 \pm 14^{* * *}$ & 4 \\
\hline 5'-Trans-MeN & $>300 * * *$ & $<1^{* * *}$ & 4 \\
\hline $5^{\prime}-C i s-\mathrm{MeN}$ & $>300 * * *$ & $<1 * * *$ & 4 \\
\hline
\end{tabular}

$n=$ the number of oocytes used

${ }^{*} P<0.05 * * P<0.01, * * * P<0.001$, comparison with nicotine. (These $P$ values were obtained from one-way ANOVA of log-transformed data with Dunnett's multiple comparison post-test.)

${ }^{t} P<0.05$, " $P<0.01$, "tt $P<0.001$, comparison of cis- and trans-enantiomers; these $P$ values were obtained from a two-tailed $t$ test and, thus, are not corrected for multiple comparisons. Et, ethyl; Me, methyl; N, nicotine; NorN, nornicotine.

which was $\sim 60 \%$ of the $I_{\max }$ for ACh. In published studies in which $\alpha 4$ and $\beta 2$ cDNAs were injected into the nucleus, the $I_{\max }$ for the high-affinity form was $30 \%-60 \%$ of the maximal ACh current response (Moroni et al., 2006). Thus, our $I_{\max }$ values for $\alpha 4 \beta 2$ receptors are consistent with previously published values for $I_{\max }$ obtained with the high-affinity $\alpha 4_{2} \beta 2_{3}$ receptor. Our more recent experiments, in which we coinjected an $\alpha 4 \beta 2$ concatemer mRNA with the $\beta 2$ mRNA, which should yield only $\alpha 4_{2} \beta 2_{3}$-like functional receptors (Supplemental Fig. 2), indicate that the near-maximal concatemeric responses for several key analogs were very similar to the maximum responses in our routine Xenopus experiments (Supplemental Fig. 3), further supporting our contention that the latter primarily assessed the properties of the high-affinity stoichiometry $\alpha 4_{2} \beta 2_{3}$ subtype.
The radioligand binding data measuring ligand affinity for $\alpha 4 \beta 2 \mathrm{AChRs}$ are unlikely to be affected by the presence of the low-affinity $\alpha 4_{3} \beta 2_{2}$ receptors, since we measured displacement at such a low concentration $(1 \mathrm{nM})$ of $\left[{ }^{3} \mathrm{H}\right]$ cytisine that few of these receptors would be occupied (Moroni et al., 2006; Tavares et al., 2012).

The variance estimates for the mean potencies $\left(\mathrm{EC}_{50}\right)$ and binding constants ( $\mathrm{K}_{\mathrm{i}}$ values) of the compounds tended to increase as their mean values increased, so we used a $\log _{10}$ transformation of the estimates to better approximate a normal distribution of the individual estimates for a compound. This resulted in more-similar variance estimates among the compounds and allowed one-way ANOVA to be used to analyze comparisons of all compounds with nicotine.

Functional and radioligand binding data for each methylnicotine will now be presented and discussed in order of the five pyrrolidinium ring atoms $1^{\prime}$ to $5^{\prime}$ (Fig. 1), numbered according to the International Union for Pure and Applied Chemistry nomenclature. Data for $\alpha 7 \mathrm{nAChRs}$ will be presented initially, since interactions of these compounds with this receptor subtype have not been previously reported.

$\mathbf{1}^{\prime}$-Methylnicotine and 1 '-Ethylnornicotine. Ample evidence exists that the monocationic form of nicotine and of most other ionizable $\mathrm{nAChR}$ agonists is the form that binds to nAChRs with highest affinity (Barlow and Hamilton, 1962; Jeng and Cohen, 1980; Kem et al., 2004). Since the published $p K_{\mathrm{a}}$ for ionization of the $1^{\prime}-\mathrm{N}$ of nicotine (8.05, Fujita et al., 1971 ) is $0.65 \mathrm{U}$ above physiologic $\mathrm{pH}$ of 7.4 , and the methylnicotine analogs were found to have similar $p K_{\mathrm{a}}$ values (Supplemental Table 1), our pharmacological data in Tables 1-6 largely reflect the properties of the monocationic species and are uncorrected for the small differences in ionization we observed for the 1'-ethyl-, 2'-methyl-, and 5'-methylnicotine analogs (see Supplemental Table 1 for estimation of the percentage of monocationic species for compounds expected to show the largest differences in ionization).

We first examined the consequences of adding an additional methyl substituent to the $1^{\prime}-\mathrm{N}$ of nicotine and found major differences between the two receptors. For $\alpha 7$ receptors, the

TABLE 4

Nicotine analog binding to mammalian $\alpha 4 \beta 2$ nAChRs measured by displacement of $\left[{ }^{3} \mathrm{H}\right]$ cytisine-specific binding Mean $\mathrm{K}_{\mathrm{i}}$ estimates \pm one sample S.D. are given.

\begin{tabular}{|c|c|c|c|c|c|c|}
\hline \multirow{2}{*}{ Compound } & \multicolumn{3}{|c|}{ Rat Brain Receptor } & \multicolumn{2}{|c|}{ Human Receptor (tsA201) } & \multirow[b]{2}{*}{$n$} \\
\hline & $\mathrm{K}_{\mathrm{i}}(\mathrm{nM})$ & -Hill Slope & $n$ & $\mathrm{~K}_{\mathrm{i}}(\mathrm{nM})$ & -Hill Slope & \\
\hline $\operatorname{Nic}(\mathrm{N})$ & $3.26 \pm 0.78$ & 0.85 & 6 & $3.53 \pm 0.92$ & 0.89 & 5 \\
\hline $1^{\prime}$-MeN & $147 \pm 18^{* * *}$ & 0.84 & 4 & $158 \pm 79^{* *}$ & 0.87 & 8 \\
\hline 1'-EtNorN & $83.1 \pm 20 * * *$ & 0.80 & 5 & $91.6 \pm 22^{* * *}$ & 1.0 & 4 \\
\hline $2^{\prime}-\mathrm{MeN}$ & $3.13 \pm 1.5$ & 1.3 & 4 & $6.65 \pm 1.7^{* *}$ & 1.4 & 4 \\
\hline 3'-Trans-MeN & $73.7 \pm 13^{* * *, \text {,tt }}$ & 0.94 & 4 & $161 \pm 37^{* * *, t \mathrm{tt}}$ & 0.92 & 6 \\
\hline $3^{\prime}-\mathrm{Cis}-\mathrm{MeN}$ & $770 \pm 71^{* * *}$ & 1.0 & 6 & $1380 \pm 400^{* * *}$ & 1.2 & 4 \\
\hline $4^{\prime}$-Trans-MeN & $14.9 \pm 5.1^{* * *}$ & 1.0 & 6 & $14.0 \pm 6.9^{* *}$ & 1.1 & 6 \\
\hline $4^{\prime}-C i s-\mathrm{MeN}$ & $24.4 \pm 7.1^{* * *, \mathrm{t}}$ & 1.1 & 6 & $32.6 \pm 16^{* *, \mathrm{t}}$ & 1.8 & 3 \\
\hline 5'-Trans-MeN & $150 \pm 26^{* * *}$ & 1.0 & 4 & $219 \pm 76^{* * *}$ & 1.0 & 4 \\
\hline $5^{\prime}$-Cis-MeN & $10,600 \pm 1620^{* *, \mathrm{tt}}$ & 0.87 & 5 & $8330 \pm 1030 * * *$, ,tt & 0.97 & 6 \\
\hline
\end{tabular}

$n=$ the number of experiments.

${ }^{*} P<0.05, * * P<0.01, * * * P<0.001$, comparison with nicotine. (These $P$ values were obtained from one-way ANOVA of log-transformed data with Dunnett's multiple comparison post-test.)

${ }^{\mathrm{t}} P<0.05$, ${ }^{\text {"P}} P<0.01$, "tt $P<0.001$, comparison of $c$ sis- and trans-enantiomers; these $P$ values were obtained from a two-tailed $t$ test and, thus, are not corrected for multiple comparisons. Et, ethyl; Me, methyl; N, nicotine; NorN, nornicotine. 
A

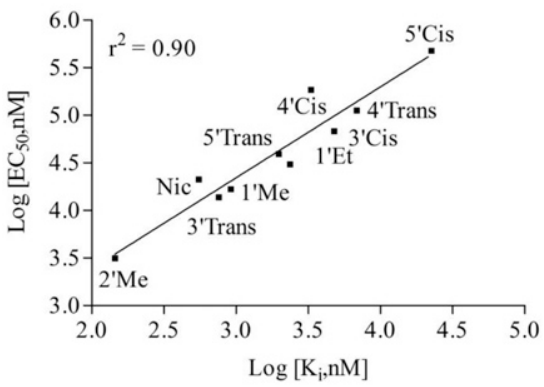

C

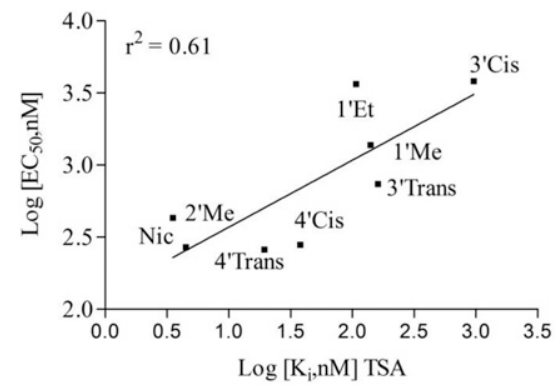

B

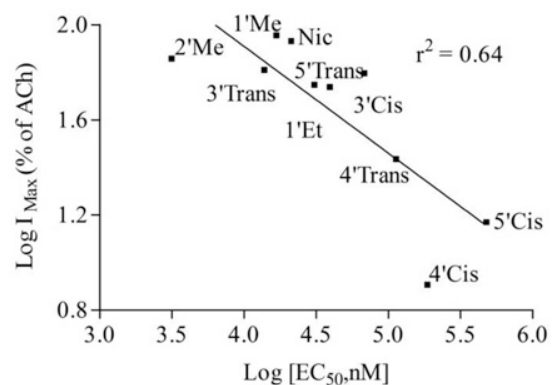

D

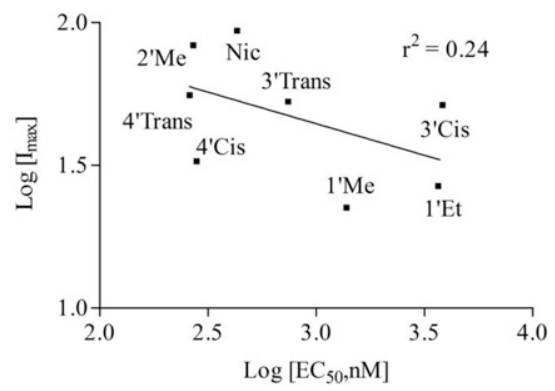

Fig. 3. Correlations between Xenopus oocyte functional and cultured cell receptor binding data. $I_{\max }$ and $\mathrm{EC}_{50}$ estimates were determined from human $\alpha 7$ receptors expressed in Xenopus oocytes using the net charge method, whereas $\mathrm{K}_{\mathrm{i}}$ values were determined by $\left[{ }^{125} \mathrm{I}\right] \mathrm{BTX}$ displacement using SH-EP1 cell membranes expressing human $\alpha 7$ receptors (A and $\mathrm{B}$ ), $\mathrm{EC}_{50}$ values from human $\alpha 4 \beta 2$ receptors expressed in oocytes, and $\mathrm{K}_{\mathrm{i}}$ values from tsA201 cell membranes (C and D). (A) Nicotine analog correlation between binding $\mathrm{K}_{\mathrm{i}}$ from $\mathrm{SH}$ EP1 cells and $\mathrm{EC}_{50}$ from $\alpha 7$ receptor Xenopus oocytes. (B) Nicotine analog correlation between $\alpha 7$ receptor net charge $\mathrm{EC}_{50}$ and $I_{\max }$ for each compound. (C) Nicotine analog correlation between and $\alpha 4 \beta 2$ receptor $\mathrm{K}_{\mathrm{i}}$ values (tsA201 cells) and $\mathrm{EC}_{50} \mathrm{~s}$ (oocytes). And (D) nicotine analog correlation between human $\alpha 4 \beta 2$ receptor $\mathrm{EC}_{50}$ and $I_{\max }$. Nicotine, Nic; TSA, tsA201 cell. Other nicotine analogs are referred to by their numerical substitution (methyl or ethyl) and chirality (cis or trans). agonist properties (Fig. 2; Table 1) and binding affinities (Table 2) of the quaternary nitrogen analog, $1^{\prime}$-methylnicotinium iodide, were similar to those of nicotine, but they were diminished at $\alpha 4 \beta 2$ receptors (Fig. 2; Tables 3 and 4). Thus, methyl quaternization of the pyrrolidinium nitrogen is well tolerated by $\alpha 7$ but not $\alpha 4 \beta 2$ nAChRs.

Replacing the $1^{\prime}-N$-methyl group of nicotine with a larger alkyl group, as in 1'-ethylnornicotine, also differentially affected agonistic properties at these two receptors. The ethyl substituent was relatively well tolerated by the $\alpha 7$ receptor: only the $I_{\max }$ was statistically different from that of nicotine (Table 1). However, at $\alpha 4 \beta 2 \mathrm{nAChRs}, 1^{\prime}$-ethylnornicotine potency and efficacy were inferior to that of nicotine (Table 3). We also found that racemic 1 -propylnornicotine displayed an almost 1000-fold decrease in potency relative to nicotine at $\alpha 4 \beta 2$ receptors, in agreement with a previous study (Glassco et al., 1994), as well as a greatly reduced potency at $\alpha 7$ receptors (results not shown). Thus, nicotine interaction with $\alpha 4 \beta 2$ receptors is particularly sensitive to the presence of bulky quantitatively alkyl groups at the $1^{\prime}-\mathrm{N}$ position.

2'-Methylnicotines. Trans-2'-methylation produced unique changes relative to the other six carbon-methylated nicotines, which displayed reduced agonist properties relative to nicotine. 2'-Methylnicotine displayed agonist properties superior

TABLE 5

Nicotine analog free energies of binding to the two human nAChRs compared with free energies of binding ( $\Delta$ Gs) predicted from AChBP crystal structure docking

The number within parentheses is the \% increase in $\Delta \mathrm{G}$ of the analog relative to the $\Delta \mathrm{G}$ for nicotine; a plus value represents a reduced affinity of the analog for the receptor relative to nicotine.

\begin{tabular}{|c|c|c|c|c|}
\hline \multirow{3}{*}{$\begin{array}{l}\text { Compound } \\
\text { Nic (N) }\end{array}$} & \multicolumn{2}{|c|}{ Human Receptor } & \multicolumn{2}{|c|}{ AChBP } \\
\hline & \multirow{2}{*}{$\begin{array}{c}\alpha 7(\mathrm{SH}-\mathrm{EP} 1 \text { Cell) } \\
8.88(0 \%)^{a}\end{array}$} & \multirow{2}{*}{ 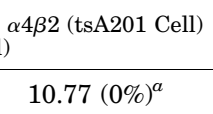 } & \multicolumn{2}{|c|}{$\begin{array}{l}\text { Aplysia } \alpha 7 \\
\text { Predicted }-\Delta \mathrm{G}(\mathrm{kcal} / \mathrm{mol})\end{array}$} \\
\hline & & & $8.88^{b}$ & $8.88^{c}$ \\
\hline $\begin{array}{l}1^{\prime}-\mathrm{MeN} \\
1^{\prime} \text {-EtNorN }\end{array}$ & $\begin{array}{l}8.58(+3 \%) \\
7.99(+10 \%)\end{array}$ & $\begin{array}{l}8.66(+20 \%) \\
8.96(+17 \%)\end{array}$ & - & - \\
\hline $2^{\prime}-\mathrm{MeN}$ & $9.72(-9 \%)$ & $10.42(+3 \%)$ & 9.21 & 6.09 \\
\hline $\begin{array}{l}3^{\prime}-\text { Trans-MeN } \\
3^{\prime}-\text { Cis-MeN }\end{array}$ & $\begin{array}{l}8.70(+2 \%) \\
7.56(+15 \%)\end{array}$ & $\begin{array}{l}8.66(+20 \%) \\
7.47(+31 \%)\end{array}$ & $\begin{array}{l}7.98 \\
1.22\end{array}$ & $\begin{array}{l}7.56 \\
4.5\end{array}$ \\
\hline $\begin{array}{l}4^{\prime}-\text { Trans-MeN } \\
4^{\prime}-\text { Cis-MeN }\end{array}$ & $\begin{array}{l}7.34(+14 \%) \\
7.79(+12)\end{array}$ & $\begin{array}{c}10.00(+7 \%) \\
9.54(+11 \%)\end{array}$ & $\begin{array}{l}8.04 \\
6.3\end{array}$ & $\begin{array}{l}6.36 \\
5.01\end{array}$ \\
\hline $\begin{array}{l}5^{\prime}-\text { Trans-MeN } \\
5^{\prime}-\text { Cis-MeN }\end{array}$ & $\begin{array}{l}8.11(+9 \%) \\
6.60(+26 \%)\end{array}$ & $\begin{array}{l}8.48(+21 \%) \\
6.47(+40 \%)\end{array}$ & $\begin{array}{l}8.37 \\
8.33\end{array}$ & $\begin{array}{l}7.16 \\
3.66\end{array}$ \\
\hline
\end{tabular}

Et, ethyl; Me, methyl; N, nicotine; NorN, nornicotine.

${ }^{a} \% \Delta \mathrm{G}$ change relative to $\Delta \mathrm{G}$ for nicotine.

${ }^{b}$ Predicted nicotine $-\Delta \mathrm{G}=34.1 \mathrm{kcal} / \mathrm{mol}$; normalized to 8.88 .

${ }^{c}$ Predicted nicotine $-\Delta \mathrm{G}=37.5 \mathrm{kcal} / \mathrm{mol}$; normalized to 8.88 
TABLE 6

Radioligand binding affinities of six additional methylnicotine analogs for rat brain $\alpha 4 \beta 2$ and $\alpha 7$ receptors

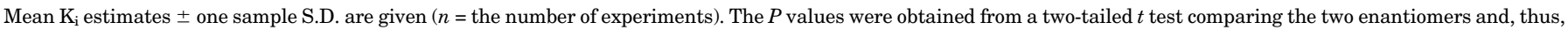
are not corrected for multiple comparisons. The four $\mathrm{Me}(\mathrm{R}) \mathrm{N}$ compounds are methylated methyl(R)-nicotines.

\begin{tabular}{|c|c|c|c|c|c|c|}
\hline \multirow{2}{*}{ Compound } & \multicolumn{3}{|c|}{$\alpha 4 \beta 2$ Receptor } & \multicolumn{3}{|c|}{$\alpha 7$ Receptor } \\
\hline & $\mathrm{K}_{\mathrm{i}}(\mathrm{nM})$ & -Hill Slope & $n$ & $\mathrm{~K}_{\mathrm{i}}(\mathrm{nM})$ & -Hill Slope & $n$ \\
\hline $\mathrm{A} 84543^{a}$ & $3.44 \pm 0.40$ & & & $340 \pm 50$ & & \\
\hline 5'-Trans-MeA84543 & $18.5 \pm 17^{\mathrm{tt}}$ & 1.0 & 4 & $603^{\mathrm{tt} \pm} \pm 170$ & 1.9 & 5 \\
\hline 5'-Cis-MeA84543 & $201 \pm 26$ & 1.0 & 3 & $2140 \pm 830$ & 1.8 & 5 \\
\hline $5^{\prime}-$ Trans $-\mathrm{Me}(\mathrm{R}) \mathrm{N}$ & $480 \pm 140^{\ddagger}$ & 1.1 & 3 & $3920 \pm 2300$ & 2.9 & 2 \\
\hline $5^{\prime}-C i s-\mathrm{Me}(\mathrm{R}) \mathrm{N}$ & $204 \pm 89$ & 1.0 & 5 & 426 & 2.8 & 1 \\
\hline $3^{\prime}-$ Trans $-\mathrm{Me}(\mathrm{R}) \mathrm{N}$ & $553 \pm 140^{\mathrm{tt}}$ & 1.1 & 4 & $6720 \pm 710^{\mathrm{tt}}$ & 3.6 & 3 \\
\hline $3^{\prime}-C i s-\mathrm{Me}(\mathrm{R}) \mathrm{N}$ & $4340 \pm 1400$ & 1.1 & 4 & $22,000 \pm 3600$ & 1.7 & 3 \\
\hline
\end{tabular}

${ }^{\mathrm{t}} P<0.05,{ }^{\text {"t }} P<0.01,{ }^{\text {"tt }} P<0.001$, comparison of cis- and trans-enantiomers (These $P$ values were obtained from a two-tailed $t$ test)

${ }^{a} \mathrm{~A} 84543 \mathrm{~K}_{\mathrm{i}} \pm$ S.E.M. binding data of Abreo et al. (1996), Ogunjirin et al. (2015) reported $\mathrm{K}_{\mathrm{i}}$ values of 0.15 and $1 \mathrm{nM}$ for A84543 and nicotine, respectively, at rat brain $\alpha 4 \beta 2$ receptors.

to nicotine at $\alpha 7$ receptors and was at least as active as nicotine at $\alpha 4 \beta 2$ receptors. $\alpha 7 \mathrm{nAChR}$ potency and equilibrium binding affinity (Table 1 ) were enhanced about 7 -fold for the human receptor in comparison with nicotine. At the $\alpha 4 \beta 2$ receptor, $2^{\prime}$-methylnicotine potency and $I_{\max }$ were not statistically different from nicotine (Table 3 ). The small increase in binding affinity at the $\alpha 4 \beta 2$ receptor was only statistically significant for the human receptor (Table 4). Our data for $2^{\prime}$-methylnicotine binding to rat brain $\alpha 4 \beta 2$ receptors was consistent with the data of Wang et al. (1998) for racemic 2 '-methylnicotine, taking into consideration that our $2^{\prime}$-methyl-(S)-nicotine has a much higher $(>40$ fold) binding affinity than $2^{\prime}$-methyl-(R)-nicotine (Kem, unpublished results).

3'-Methylnicotines. Cis-3'-methylnicotine displayed less potency ( $\sim 3$-fold at $\alpha 7$ and $\sim 10$-fold at $\alpha 4 \beta 2$ receptors) relative to nicotine (Fig. 2; Tables 1 and 3). There was also a statistically significant ( $\sim 2$-fold) decrease in the $\alpha 4 \beta 2$ receptor $I_{\max }$. Cis-3'-methylnicotine displayed less affinity for $\alpha 7$ (approximately 4-fold for rat and 8-fold for human) and $\alpha 4 \beta 2$ (approximately 200-fold less for rat and 400-fold less for human) receptors relative to nicotine (Tables 2 and 4). Although the affinity of trans-3'-methylnicotine for the $\alpha 7$ receptor was similar to that of nicotine, its affinity for $\alpha 4 \beta 2$ receptors was $\geq 30$-fold less than for nicotine.

$4^{\prime}$-Methylnicotines. At both receptors (especially the $\alpha 7$ ), the efficacies of both $4^{\prime}$-methylnicotines were greatly reduced relative to nicotine (Fig. 2; Tables 1 and 3 ). Whereas the potencies of the two enantiomers were inferior to that of nicotine at $\alpha 7$ receptors, on the human $\alpha 4 \beta 2$ receptor the potencies were not significantly different from that of nicotine. Relative binding affinities of the two enantiomers at the two receptors differed: at both $\alpha 7$ receptors, the cis-enantiomer displayed the highest affinity, but at rat and human $\alpha 4 \beta 2$ receptors, the trans-enantiomer displayed the highest affinity.

5'-Methylnicotines. Analysis of the pharmacological properties of cis-5'-methylnicotine revealed its limited ability to interact with $\alpha 4 \beta 2$ receptors. Agonist potency was reduced $>700$-fold, and $I_{\max }$ was reduced $>100$-fold (Table 3 ). The binding $\mathrm{K}_{\mathrm{i}}$ values for rat and human $\alpha 4 \beta 2$ receptors were also increased $>2000$-fold and >700-fold, respectively (Table 4). Previous radioligand binding studies also indicated that methylation at this position had detrimental effects on nicotine binding affinity for rat brain high-affinity $(\alpha 4 \beta 2)$ receptors and that the binding $\mathrm{K}_{\mathrm{i}}$ of trans-5'-methylnicotine was less affected than that of the cis-form (Lin et al., 1994; Wang et al., 1998).

Although cis-5'-methylnicotine also displayed the greatest reduction in interaction with $\alpha 7$ receptors, trans-5'-methylnicotine was a relatively potent agonist, with potency decreasing only 2 - to 3 -fold and $I_{\max }$ decreasing $\sim 1.5$-fold relative to nicotine (Table 1). Binding affinities for the human and rat $\alpha 7 \mathrm{nAChRs}$ were only decreased $\sim 3$-fold relative to nicotine (Table 2 ).

Relationships between Receptor Affinity and Receptor Potency. Compound $\mathrm{EC}_{50}=\mathrm{K}_{\mathrm{d}} /(\mathrm{E}+1)$, where $\mathrm{K}_{\mathrm{d}}$ is the equilibrium dissociation constant for initial binding to the inactive state, and $\mathrm{E}$ is the equilibrium constant associated with receptor activation (Auerbach, 2016). If $K_{i}$ estimates are related to the $\mathrm{K}_{\mathrm{d}}$, then our $\mathrm{EC}_{50}$ estimates might show some relationship to the $K_{i}$ values, at least for compounds displaying low $\mathrm{E}$ values. We plotted $\mathrm{K}_{\mathrm{i}}$ versus $\mathrm{EC}_{50}$ estimates for each alkylnicotine to determine whether they might be related (Fig. 3, A and C). We used $\mathrm{EC}_{50}$ estimates obtained with the net charge method of analysis for $\mathrm{EC}_{50}$ and $I_{\max }$ characterization of the functional properties of the human $\alpha 7$ receptor in this figure. Both the $\alpha 7$ and $\alpha 4 \beta 2$ plots showed a relatively strong correlation between these two variables (Fig. 3A, $\alpha 7$ correlation coefficient $\mathrm{r}^{2}=0.90$; Fig. $3 \mathrm{C}, \alpha 4 \beta 2 \mathrm{r}^{2}=0.61$ ). Since the $\alpha 7$ net charge-determined $\mathrm{EC}_{50}$ values (Table 1) were $\sim 3$-fold less than the peak current $\mathrm{EC}_{50}$ estimates, using our standard 2-second agonist exposure (and 10-fold less for a 20 second exposure; Kem, unpublished results), the actual $\alpha 7$ receptor $\mathrm{EC}_{50}$ for each compound may be as much as 10-fold less than the peak current $\mathrm{EC}_{50}$ reported in Table 1 and used in Fig. $3 \mathrm{~A}$ of this figure.

It was recently reported that there is a linear relationship between $\log I_{\max }$ and $\log \mathrm{EC}_{50}$ for agonists at the mouse neuromuscular nAChR - that high efficacy is directly correlated with high potency (Auerbach, 2016). In spite of the differences in how efficacy was measured (single channel recording in the Auerbach study and oocyte net charge response here), a similar correlation was observed with our $\alpha 7$ data (Fig. 3B, $\mathrm{r}^{2}=0.67$ ). In Fig. 3B, the $I_{\max }$ estimates for the most efficacious compounds ( 2 '-MeNic, $1^{\prime}$-MeNic, and Nic) are very similar, although their $\mathrm{EC}_{50}$ values differ considerably, which would not be predicted from the Auerbach equation; it seems likely that desensitization may limit the $I_{\max }$ values measured for these highly potent agonists under our experimental conditions. In contrast to the $\alpha 7$ plot in $3 \mathrm{~B}$, 


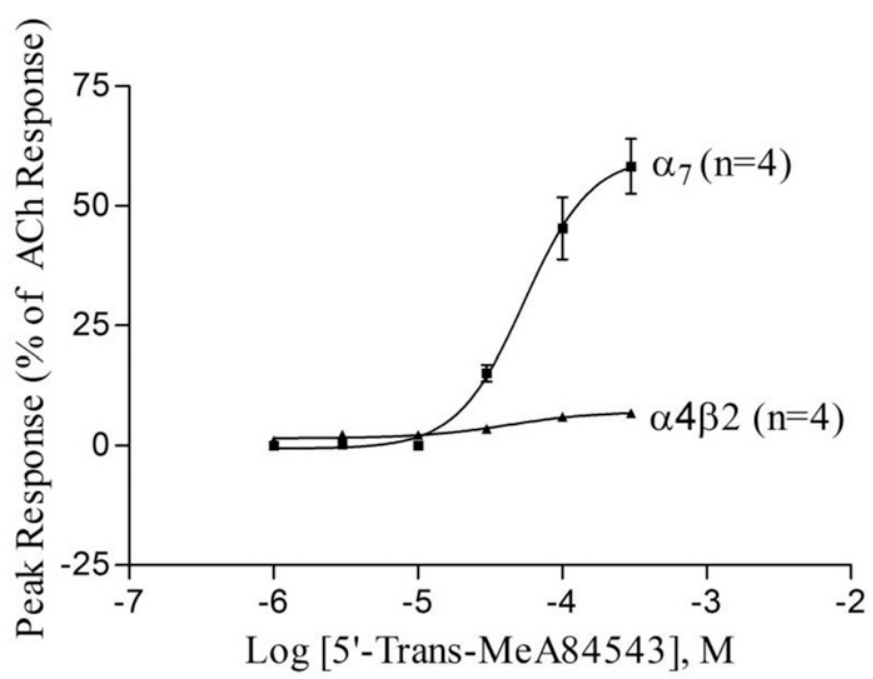

Fig. 4. Concentration-response curves for $5^{\prime}$-trans-methylA 84543 stimulation of human $\alpha 4 \beta 2$ and $\alpha 7 \mathrm{nAChRs}$ expressed in Xenopus oocytes. The error bars indicate \pm one S.E.M. (The 5'-cis-methylA84543 enantiomer was much less active: at $30 \mu \mathrm{M}$, the peak $\alpha 7$ response was approximately $10 \%$ of the $1 \mathrm{mM}$ ACh response, and the $\alpha 4 \beta 2$ response was $\sim 0 \%$ of the $100 \mu \mathrm{M}$ ACh response.)

the $\alpha 4 \beta 2$ plot showed much more scatter when plotted in an identical fashion (Fig. 3D, $\mathrm{r}^{2}=0.24$ ).

Modeling Methylnicotine Interaction with the Molluscan ACh Binding Proteins. Since high-resolution crystal structures of the two nAChRs are still unavailable, we attempted to predict the binding poses and relative docking free energies of the various methylnicotines using the Brookhaven Protein Data Bank Lymnaea AChBP-nicotine 1UW6 structure (Celie et al., 2004) and the mutated $A$. californica AChBP-epibatidine 3SQ6 structure, in which the binding site was mutated to be similar to the $\alpha 7$ site (Li et al., 2011). In the 1UW6 structure, the cis-side of the nicotine pyrrolidinium ring comes in closest proximity with the AChBP Trp143 indole side chain, and the $1^{\prime}-\mathrm{N}$ proton is also very near (2.6 ̊) the Trp143 peptide carbonyl group and is assumed to form an $\mathrm{H}$-bond with it (Celie et al., 2004). In contrast, the 2 '-carbon of nicotine is not in close contact with any nonwater atoms in the AChBP binding site. Actually, the 2 -methyl is oriented toward the disulfide bond between the vicinyl half-cystines in the C-loop. The structures of the various methylnicotines (as monocations) were energyminimized and docked to both AChBPs after removing the crystallized ligands from their respective $\mathrm{ACh}$ binding sites. The relative energies for docking the various methylnicotines (Table 5) to both AChBP structures predicted many of the differences in binding affinity that were observed, particularly when two of the most persistently bound water molecules in the Lymnaea AChBP-nicotine complex (Amiri et al., 2007) were retained within the binding site during docking (see Supplemental Table 2 for fit estimates). For the $3^{\prime}$ - and 5'-methylnicotines, the docking score of the cismethyl enantiomer predicted a less favorable free energy of binding relative to the trans-enantiomer, and cis-5' -methylnicotine was predicted to have the least-favorable free energy of binding of all the methyl analogs to both AChBPs (Table 5). The nicotine compound predictions for the Aplysia AChBP- $\alpha 7$ chimera binding site, containing no water molecules, were similar to those obtained for the Lymnaea $\mathrm{AChBP}$.
Comparison of Free Energy Changes Associated with Compound Binding to Human nAChRs with Predicted Free Energy Changes for Binding to AChBPs. The $\Delta \mathrm{Gs}$ (Table 5) of the various analogs relative to the $\Delta \mathrm{G}$ for nicotine binding at the same receptor site, expressed within the parentheses as a percent change, are most salient. The relative $\Delta \mathrm{G}$ changes associated with methylation were much greater for $\alpha 4 \beta 2$ receptors than for $\alpha 7$ receptors. The major exception was 2 -methylnicotine, which actually showed a greater free energy decrease (lower $K_{i}$ ) relative to nicotine at the $\alpha 7$ receptor. This was only predicted for the Aplysia AChBP- $\alpha 7$ chimera, whose orthosteric binding site most resembles the $\alpha 7$ binding site. Another important observation was that the free energy of binding difference $(-1.9 \mathrm{kcal} / \mathrm{mol})$ for nicotine, between the human $\alpha 4 \beta 2$ receptor $(\Delta \mathrm{G}=-10.8 \mathrm{kcal} / \mathrm{mol})$ and the $\alpha 7$ receptor $(\Delta \mathrm{G}=-8.9 \mathrm{kcal} / \mathrm{mol})$, almost disappeared in free energy comparisons for most other analogs other than the $1^{\prime}$ $N$-methynicotinium and $1^{\prime}-N$-ethylnornicotine. This important observation will be discussed later.

Influence of Methyl Substituent Configuration on Receptor Interaction in Other Methylated Nicotine Analogs. Abreo et al. (1996) synthesized and tested the nicotine analog A84543, in which an oxymethylene group forms a bridge between the 3-pyridyl ring and the 2 '-(S) position of the pyrrolidinium ring so that the pyridyl ring retains the same chirality as in nicotine. This compound displayed very high affinity and potency at $\alpha 4 \beta 2$ receptors, exceeding that of nicotine, indicating that this receptor not only tolerates a greater distance between the two nicotine ring $\mathrm{N}$ atoms but also binds this compound more readily than nicotine. To determine whether A84543 would be similarly affected by 5 '-methylation, we synthesized (see Supplemental Data) and tested the two 5'-methylA84543 diastereomers. The rat brain $\alpha 4 \beta 2$ receptor affinity (Table 6) of trans-5'-methylA84543 was 7-fold higher than the cis$5^{\prime}$-methylA84543. The rat brain high-affinity receptor $\mathrm{K}_{\mathrm{i}}$ for A84543 has been reported to be $0.15 \pm 0.01$ (Abreo et al., 1996) and $3.44 \pm 0.40 \mathrm{nM}$ (Ogunjirin et al., 2015), and the $\alpha 7$ receptor $\mathrm{K}_{\mathrm{i}}$ was reported to be $340 \pm 50 \mathrm{nM}$ (Ogunjirin et al., 2015). Although the difference we observed between the two methylated A84543 enantiomers was approximately $10 \times$ less than it was for the $5^{\prime}$ methylnicotines, it is clear that the preferential binding of the trans-5'-methylnicotine also applies to trans $-5^{\prime}$-methylA85443. Like A84543, both methyl enantiomers interacted with $\alpha 7$ receptors with much lower affinity relative to $\alpha 4 \beta 2$ receptors, with the cis-enantiomer showing the least affinity and potency (Table 6). The efficacies of trans-5'methylA84543 (Fig. 4) at human $\alpha 7$ and $\alpha 4 \beta 2$ receptors were similar to those of trans $-5^{\prime}$-methylnicotine (Tables 1 and 3 ).

Since we had prepared racemic $3^{\prime}$ - and 5 '-methylnicotines and then separated the diastereomeric (R)- and (S)-methylnicotines, this afforded the opportunity of determining whether the relative or absolute configurations of these two methyl substituents are critical for optimal interaction with the receptors. Our binding data shows that at the $3^{\prime}$ position, the same relative configuration (trans) allows the highest affinity, irrespective of the pyridyl ring substituent configuration. However, it is the absolute configuration of the $5^{\prime}$-methyl substituent that determines relative activity, since the substituent in cis-5'-methyl 
(R)-nicotine has the same absolute configuration as the methyl in trans-5'-methyl-(S)-nicotine.

\section{Discussion}

Dominant Role of the Cationic $\boldsymbol{N}$-Alkyl Moiety. Ionization of the most basic $\mathrm{N}$ atom is essential for efficient binding of nicotine and most nicotinoids to various AChRs and AChBPs. The pyrrolidinyl $\mathrm{N}$ in nicotine has been reported to possess a $p K_{\mathrm{a}}$ of 8.05 and a pyridyl ring $\mathrm{N} p K_{\mathrm{a}}$ of 3.85 (Fujita et al., 1971). Thus, at physiologic $\mathrm{pH}$, there will be a mixture of the monocationic and unionized pyrrolidinyl forms, and their relative solution concentrations will depend upon the $\mathrm{pH}$. Under the ionic strength conditions of our radioligand binding measurements, the nicotine $p K_{\mathrm{a}}$ was 8.00 , and its ionization was $80 \%$ at $\mathrm{pH} 7.4$ (Supplemental Table 1 ). The $p K_{\mathrm{a}}$ of the pyrrolidinium $\mathrm{N}$ was enhanced the most (to 8.44) by replacing the $1^{\prime}-N$-methyl with an ethyl group. Methylating the $2^{\prime}$ - or $5^{\prime}$ positions produced very small increases in ionization at $\mathrm{pH}$ 7.4. Methylation at the $3^{\prime}$ or $4^{\prime}$ position would not be predicted to have a significant inductive effect on the $p K_{\mathrm{a}} 1$.

Adding an additional methyl to the $1^{\prime}-\mathrm{N}$ of nicotine greatly diminished interaction with the $\alpha 4 \beta 2$ receptor without much effect on interaction with the $\alpha 7$ receptor. Substituting the larger ethyl moiety for the $1^{\prime}-N$-methyl group, as in $1^{\prime}-N$-ethylnornicotine, was deleterious for interaction with both receptors, especially the $\alpha 4 \beta 2$ receptor. Formation of the $1^{\prime}-N$-Trp B carbonyl hydrogen bond seems to be important for nicotine binding to $\alpha 4 \beta 2$ receptors (Xiu et al., 2009; Puskar et al., 2011). The high affinity of nicotine for the $\alpha 4 \beta 2$ receptor may, at least partially, be due to this hydrogen bond, which seems less important for interaction with the $\alpha 7 \mathrm{nAChR}$ subtype and may not be essential (Puskar et al., 2011; Van Arnam et al., 2013). The lesser effects on $\alpha 7$ interaction of these two $1^{\prime}-\mathrm{N}$ modifications suggest that a small increase in bulk of the pyrrolidinium group does not adversely affect cation- $\pi$ binding. The highly detrimental influence of increasing the bulk of substituents at the $1^{\prime}-\mathrm{N}$ for $\alpha 4 \beta 2$ receptor interaction may be due to these bulky substituents interfering with formation of this hydrogen bond.

2'-Methylation Uniquely Increases Interaction with the $\alpha 7$ Receptor without Adversely Affecting Interaction with the $\alpha 4 \beta 2 \mathrm{nAChR}$. Unexpectedly, methylation at the 2 '-carbon, which also connects the two rings, significantly enhances binding and agonist potency at the $\alpha 7 \mathrm{nAChR}$ without significantly affecting interaction with the $\alpha 4 \beta 2$ nAChR. The 2'-methyl may form a hydrophobic interaction with some groups that may favor formation of an $\mathrm{H}$-bond between the $1^{\prime}-\mathrm{NH}+$ and the receptor, which otherwise seems to be absent. If binding site waters are present in the vicinity of the $1^{\prime}-\mathrm{NH}$ of nicotine, they might be displaced by a methyl substituent like the 2'-methyl (Barratt et al., 2006; Leung et al., 2012). Water molecules are present in the agonist-bound AChBP as well as in the agonist-free state of the AChBP binding site (Celie et al., 2004; Amiri et al., 2007), and it has been found (Forli and Olson, 2012; this study) that better docking predictions can be obtained when persistent water molecules observed in the nicotine-AChBP crystal binding site are included in the computer docking. The actual basis for the potentiating effect of the 2'-methyl substituent can only be determined by additional experimental and computational studies.

3'-Cis-Methylation Reduces Agonist Activity More than 3'-Trans-Methylation. Since the pyrrolidinium 3'-carbon is next to the inter-ring bonding 2 '-carbon, it was predicted that its methylation would alter the energy profile for inter-ring torsion and might even prevent the compound from attaining an optimal conformation for agonistic binding and to the receptor. Although both 3 '-methylnicotines were less active than nicotine, we found that that trans-3'-methylnicotine was significantly more active than $c i s-3^{\prime}$-methylnicotine at both receptors. The thermodynamically preferred inter-ring angles for cis-3'- and trans-3'-methylnicotine and for nicotine are predicted to be very similar, but the energy barrier for rotation around the $\mathrm{C} 2$ ' $-\mathrm{C} 3$ bond is much higher $(60 \mathrm{kcal} / \mathrm{mol})$ for cis-3'-methylnicotine compared with $14 \mathrm{kcal} / \mathrm{mol}$ for trans3 '-methylnicotine (Seeman, 1984). One possibility is that the two rings must be able to move with respect to each other in the binding or receptor activation processes, and the presence of the $3^{\prime}$-methyl substituent to varying degrees inhibits these movements. The data in Table 6, indicating that the relative configuration of the $3^{\prime}$-methyl group is more important for activity and binding than its absolute configuration, is consistent with this interpretation.

5 '-Cis-Methylation Causes a Drastic Loss of Activity at Both nAChRs. The 5 '-position of the pyrrolidinium ring is adjacent to the $1^{\prime}-N$-hydrogen, which $\mathrm{H}$-bonds to the peptide carbonyl of Trp 143 at the Lymnaea AChBP and by inference at Trp B of the $\alpha 4 \beta 2 \mathrm{nAChR}$ (Xiu et al., 2009; Blum et al., 2010). The H-bond does not seem to be present or very strong at $\alpha 7$ receptors, at least for $\mathrm{ACh}$, epibatidine, and varenicline (van Arnam et al., 2013). Since the 5'-cis-hydrogen of nicotine abuts the Trp 143 side chain in AChBP, we suggest that cismethylation at this site significantly lowers the free energy change associated with nicotine's H-bonding to the equivalent Trp B (residue 149) in the $\alpha 4 \beta 2$ receptor. Theoretical calculations of the positive charge density of the various carbon atoms in the pyrrolidinium ring of nicotine indicate that the positive charge is less centered on the pyrrolidinyl $\mathrm{N}$ than on the three $\mathrm{C}$ atoms $\left(1^{\prime}, 2^{\prime}\right.$, and $5^{\prime}$ ) attached to the nicotine $1^{\prime}-\mathrm{N}$ (Elmore and Dougherty, 2000). Regardless of mechanism, the significant diminution in $5^{\prime}$-cismethylnicotine binding to both receptors indicates that the $5^{\prime}$ carbon occupies a very critical position that can exert much control over nicotine's interaction with these receptors. The superior activity of 5'-trans-methylA84543 relative to 5'-cis-methylA84543 (Fig. 4; Table 6) is consistent with the notion that the binding orientation of this compound, although it contains an oxymethylene bridge between the pyridyl and pyrrolidinyl rings, is very similar to that of nicotine. Our data regarding the relative affinities of the $5^{\prime}$ methyl-(R)-nicotine enantiomers indicate that it is the absolute configuration of the 5 -methyl group that determines the relative affinities of these enantiomers for both receptors.

The effects of $5^{\prime}$-methylation were greatest on nicotine's interaction with the $\alpha 4 \beta 2 \mathrm{nAChR}$ receptor. Based on the earlier radioligand binding studies with some of these nicotine analogs on $\alpha 4 \beta 2$ receptors, we anticipated that all methylations would diminish nicotine's agonistic properties. Our radioligand binding data demonstrated a preferential reduction in binding of the $3^{\prime}$-cis- and $5^{\prime}$-cis-methylated nicotines on both receptors, as well as for cis-4'-methylnicotine binding to the rat $\alpha 4 \beta 2$ (but not the $\alpha 7$ receptor). Although the molecular basis for this behavior is not yet known, it suggests that interaction of the cis-side of the pyrrolidinium ring with a part of the receptor is of paramount importance. It seems likely, based on the close proximity of the cis-side of the pyrrolidinium ring to Trp 143 in AChBPs and Trp B in the $\alpha 4 \beta 2 \mathrm{X}$-ray 
structure (Morales-Perez et al., 2016), that cis-methylation generally interferes with nicotine's interaction with this component of the aromatic "box." The lesser influence of cismethylation on interaction with the $\alpha 7$ receptor could be due to the lesser importance of $1^{\prime}-\mathrm{NH}+$ hydrogen bonding to Trp B and/or the cation- $\pi$ bonding forces between nicotine and this receptor being directed toward an adjacent Tyr in the aromatic box (Dougherty et al., 2011).

The Docking of Nicotine and Its Methylated Analogs to AChBPs. The solution conformation of nicotine has been the subject of extensive experimental and theoretical investigations over the last few decades. NMR and theoretical studies have provided strong evidence that the preferred conformation of nicotine in aqueous solution is one in which the two rings of nicotine are twisted with respect to each other (Chynoweth et al., 1973; Pitner et al., 1978; Elmore and Dougherty, 2000). The four carbon atoms of the pyrrolidinium ring are in a relatively planar "envelope" conformation in crystalline and aqueous solution conditions. Although the 1'$N$-methyl group of nicotine is capable of inversion, its transorientation with respect to the pyridyl ring substituent is of slightly lower free energy in solution. The relative positions of the two rings of nicotine in the Lymnaea AChBP crystal structure are very similar to that observed for nicotine in solution or in a vacuum, except that the $N$-methyl is cis- with respect to the pyridyl ring (Celie et al., 2004).

Comparison of the experimental free energies of binding of the various analogs (Table 5) revealed some interesting similarities in the binding energies of the $1^{\prime}-3^{\prime}-, 4^{\prime}-$, and $5^{\prime}-$ methylated nicotines on both receptors. Although the functional properties differed, the measured $-\Delta \mathrm{G}$ ( $\mathrm{kcal} / \mathrm{mol})$ values for $1^{\prime}$-methylnicotinium and both $3^{\prime}$-methylnicotines and both $5^{\prime}$-methylnicotines were very similar for the two receptors. It is tempting to interpret the much-reduced binding of these analogs to the $\alpha 4 \beta 2$ receptor, such that they bind with similar affinity to the $\alpha 7$ receptor, as being due to their inability to form the 1 '-NH hydrogen bond with the $\operatorname{Trp} \mathrm{B}$ peptide carbonyl in this receptor.

Concluding Remarks. Although similarities in methylation effects are also of general interest for understanding the interaction of nicotine with $\mathrm{AChRs}$, if selective enhancement or diminution of activity at one of the $\mathrm{nAChR}$ subtypes is desired in the design of new nicotinic drugs, then the differences become of paramount interest. Central nervous system drug design has largely focused on development of drug candidates selective for either $\alpha 4 \beta 2$ or $\alpha 7$ receptors. Drug design using nicotine as the lead compound has focused on improving selectivity for the high-affinity heteromeric receptor subtypes, but our study demonstrates that the nicotine scaffold is capable of being modified so as to increase its interactions with $\alpha 7 \mathrm{nAChRs}$. Enhancing cognitive function by separately stimulating a particular brain $\mathrm{nAChR,} \alpha 4 \beta 2$ or $\alpha 7$, has been a therapeutic goal for at least two decades, but a maintained occupation of either $\alpha 4 \beta 2$ or $\alpha 7$ receptors seems to produce suboptimal stimulation of cognitive processes in humans (Kem et al., 2018). The two major nAChR subtypes are widely expressed in the brain, often in different parts of the same neuron or within different neurons in a common circuit. Our data for 2 -methylnicotine suggest that it may be possible to concurrently stimulate both receptors at an appropriate brain concentration. A dual receptor stimulation strategy might provide a more powerful cognitive effect than when only one of the receptor subtypes is stimulated. There are some recent studies that suggest that this may be a promising approach, as long as adverse effects exerted through autonomic or neuromuscular nAChRs can be avoided (Potasiewicz et al., 2019; Sun et al., 2019).

By measuring binding affinities of the various nicotine analogs on both rat and human forms of each receptor, we have shown that these compounds display almost identical interactions with receptors of the two species. Some agonists, such as 3-(2,4-dimethoxybenzylidene)-anabaseine, display differences in their interactions with rat and human $\alpha 7 \mathrm{nAChRs}$ (Kem et al., 2004). The nearly identical binding behavior of the nicotine analogs in receptors of both species should facilitate behavioral predictions for humans based on rat models.

Some of the nicotine analogs considered in this paper have already been tested in rats and were found to reduce nicotine self-administration (Rowland et al., 2008). Of particular interest is the ability of trans-5'-methylnicotine to inhibit selfadministration of nicotine, in spite of its greatly diminished affinity for $\alpha 4 \beta 2$ receptors. We recently learned that this compound is a relatively potent partial agonist at $\alpha 6 \beta 2^{*}$ nAChRs (Kem et al., unpublished results). Thus, some of the methylnicotines may interact differently with other nAChR subtypes than would be predicted from our current studies with the two major brain nAChRs.

Our study has revealed important differences as well as similarities in the orthosteric binding sites of $\alpha 4 \beta 2$ and $\alpha 7$ nAChRs that may be useful in designing new drug candidates based on the nicotine scaffold. "Dougherty"-type analyses (Cashin et al., 2005; Davis and Dougherty, 2015), investigating the effects of introducing electron-withdrawing substituents on Trp B and other members of the binding site "aromatic box," are likely to provide additional insights into the interactions of some of these methylnicotines and how they differ from nicotine. Crystal structures, especially of 2 '-methylnicotines and $5^{\prime}$-trans-methylnicotines bound to AChBPs, $\alpha 4 \beta 2$ and $\alpha 7$ receptors, would also be informative.

\section{Acknowledgments}

We thank Steve Hagan for use of his spectropolarimeter, C.-K. Tu for assistance with computer analysis associated with the $p K_{\mathrm{a}}$ determinations, Claire Stokes for advice on Xenopus oocyte preparation and mRNA injection, and Roger Papke for assistance with Pclamp software. Portions of this investigation were part of the dissertation of K.W.A. (Wildeboer, 2005).

\section{Authorship Contributions}

Participated in research design: Xing, Andrud, Jahn, Corsino, Slavov, Lindstrom, Kem.

Conducted experiments: Xing, Andrud, Cho, Jahn, Lu, Habibi, Corsino, Slavov, Kem.

Contributed new reagents or analytic tools: Slavov, Lindstrom, Lukas.

Performed data analysis: Xing, Andrud, Jahn, Lu, Cho, Habibi, Corsino, Slavov, Lindstrom, Kem.

Wrote or contributed to the writing of the manuscript: Xing, Jahn, Lu, Slavov, Kem.

\section{References}

Abreo MA, Lin N-H, Garvey DS, Gunn DE, Hettinger AM, Wasicak JT, Pavlik PA Martin YC, Donnelly-roberts DL, Anderson DJ, et al. (1996) Novel 3-Pyridyl ethers with subnanomolar affinity for central neuronal nicotinic acetylcholine receptors. J Med Chem 39:817-825.

Allen WJ, Balius TE, Mukherjee S, Brozell SR, Moustakas DT, Lang PT, Case DA, Kuntz ID, and Rizzo RC (2015) DOCK 6: impact of new features and current docking performance. J Comput Chem 36:1132-1156. 
Amiri S, Sansom MSP, and Biggin PC (2007) Molecular dynamics studies of AChBP with nicotine and carbamylcholine: the role of water in the binding pocket. Protein Eng Des Sel 20:353-359.

Auerbach A (2016) Dose-response analysis when there is a correlation between af finity and efficacy. Mol Pharmacol 89:297-302.

Barratt E, Bronowska A, Vondrásek J, Cerný J, Bingham R, Phillips S, and Homans SW (2006) Thermodynamic penalty arising from burial of a ligand polar group within a hydrophobic pocket of a protein receptor. J Mol Biol 362:994-1003.

Barlow RB and Hamilton JT (1962) Effects of ph on the activity of nicotine and nicotine monomethiodide on the rat diaphragm preparation. $\mathrm{Br} J$ Pharmacol Chemother 18:543-549.

Bertrand D, Lee C-H, Flood D, Marger F, and Donnelly-Roberts D (2015) Therapeutic potential of $\alpha 7$ nicotinic acetylcholine receptors. Pharmacol Rev 67:1025-1073.

Black JW, Duncan WA, Durant CJ, Ganellin CR, and Parsons EM (1972) Definition and antagonism of histamine H 2 -receptors. Nature 236:385-390.

Blum AP, Lester HA, and Dougherty DA (2010) Nicotinic pharmacophore: the pyridine $\mathrm{N}$ of nicotine and carbonyl of acetylcholine hydrogen bond across a subunit interface to a backbone NH. Proc Natl Acad Sci USA 107:13206-13211.

Bouzat C, Lasala M, Nielsen BE, Corradi J, and Esandi MDC (2018) Molecular function of $\alpha 7$ nicotinic receptors as drug targets. $J$ Physiol 596:1847-1861.

Burghaus L, Schütz U, Krempel U, Lindstrom J, and Schröder H (2003) Loss of nicotinic acetylcholine receptor subunits alpha4 and alpha7 in the cerebral cortex of Parkinson patients. Parkinsonism Relat Disord 9:243-246.

Cashin AL, Petersson EJ, Lester HA, and Dougherty DA (2005) Using physical chemistry to differentiate nicotinic from cholinergic agonists at the nicotinic acetylcholine receptor. J Am Chem Soc 127:350-356.

Celie PHN, van Rossum-Fikkert SE, van Dijk WJ, Brejc K, Smit AB, and Sixma TK (2004) Nicotine and carbamylcholine binding to nicotinic acetylcholine receptors as studied in AChBP crystal structures. Neuron 41:907-914.

Changeux JP (2012) The nicotinic acetylcholine receptor: the founding father of the pentameric ligand-gated ion channel superfamily. J Biol Chem 287:40207-40215.

Chynoweth KR, Ternai B, Simeral LS, and Maciel GE (1973) Nuclear magnetic resonance studies of the conformation and electron distributions in nicotine and in acetylcholine. Mol Pharmacol 9:144-151.

Dellisanti CD, Yao Y, Stroud JC, Wang ZZ, and Chen L (2007) Crystal structure of the extracellular domain of $\mathrm{nAChR} \alpha 1$ bound to $\alpha$-bungarotoxin at $1.94 \mathrm{~A}$ resolution. Nat Neurosci 10:953-962.

Davis MR and Dougherty DA (2015) Cation- $\pi$ interactions: computational analyses of the aromatic box motif and the fluorination strategy for experimental evaluation. Phys Chem Chem Phys 17:29262-29270.

Dukat M, Fiedler W, Dumas D, Damaj I, Martin BR, Rosecrans JA, James JR and Glennon RA (1996) Pyrrolidine-modified and 6-substituted analogs of nicotine: a structure-affinity investigation. Eur J Med Chem 31:875-888.

Elmore DE and Dougherty DA (2000) A computational study of nicotine conformations in the gas phase and in water. J Org Chem 65:742-747.

Forli S and Olson AJ (2012) A force field with discrete displaceable waters and desolvation entropy for hydrated ligand docking. J Med Chem 55:623-638.

Fujita T, Nakajima M, Soeda Y, and Yamaoto I (1971) Physicochemical properties of biological interest of nicotine and its related compounds. Pestic Biochem Physiol 1: 151-162

Glassco W, May EL, Damaj MI, and Martin BR (1994) In vivo and in vitro activity of some N-substituted (+)-nornicotine analogs. Med Chem Res 4:273-282.

Jeng AY and Cohen JB (1980) Agonists of Torpedo nicotinic receptors: essential role of a positive charge. Ann N Y Acad Sci 358:370-373.

Kem WR, Mahnir VM, Prokai L, Papke RL, Cao X, LeFrancois S, Wildeboer K Prokai-Tatrai K, Porter-Papke J, and Soti F (2004) Hydroxy metabolites of the Alzheimer's drug candidate 3-[(2,4-dimethoxy)benzylidene]-anabaseine dihydrochloride (GTS-21): their molecular properties, interactions with brain nicotinic receptors, and brain penetration. Mol Pharmacol 65:56-67.

Kem WR, Olincy A, Johnson L, Harris J, Wagner BD, Buchanan RW, Christians U, and Freedman R (2018) Pharmacokinetic limitations on effects of an alpha7nicotinic receptor agonist in schizophrenia: randomized trial with an extendedrelease formulation. Neuropsychopharmacology 43:583-589.

Kim KH, Lin N-H, and Anderson DJ (1996) Quantitative structure-activity relationships of nicotine analogues as neuronal nicotinic acetylcholine receptor ligands. Bioorg Med Chem 4:2211-2217.

Kuryatov A, Luo J, Cooper J, and Lindstrom J (2005) Nicotine acts as a pharmacological chaperone to up-regulate human alpha4beta2 acetylcholine receptors. $M o$ Pharmacol 68:1839-1851.

Leung CS, Leung SS, Tirado-Rives J, and Jorgensen WL (2012) Methyl effects on protein-ligand binding. $J$ Med Chem 55:4489-4500.

Li S-X, Huang S, Bren N, Noridomi K, Dellisanti CD, Sine SM, and Chen L (2011) Ligand-binding domain of an $\alpha 7$-nicotinic receptor chimera and its complex with agonist. Nat Neurosci 14:1253-1259.

Lin N-H, Carrera GM Jr., and Anderson DJ (1994) Synthesis and evaluation of nicotine analogs as neuronal nicotinic acetylcholine receptor ligands. J Med Chem 37:3542-3553.

Martin LF, Kem WR, and Freedman R (2004) Alpha-7 nicotinic receptor agonists: potential new candidates for the treatment of schizophrenia. Psychopharmacology (Berl) 174:54-64.

Morales-Perez CL, Noviello CM, and Hibbs RE (2016) X-ray structure of the human $\alpha 4 \beta 2$ nicotinic receptor. Nature 538:411-415.

Moretti M, Zoli M, George AA, Lukas RJ, Pistillo F, Maskos U, Whiteaker P, and Gotti $\mathrm{C}(2014)$ The novel $\alpha 7 \beta 2$-nicotinic acetylcholine receptor subtype is expressed in mouse and human basal forebrain: biochemical and pharmacological characterization. Mol Pharmacol 86:306-317.

Moroni M, Zwart R, Sher E, Cassels BK, and Bermudez I (2006) Alpha4beta2 nicotinic receptors with high and low acetylcholine sensitivity: pharmacology, stoichiometry, and sensitivity to long-term exposure to nicotine. Mol Pharmacol $\mathbf{7 0}$ $755-768$.

Nelson ME, Kuryatov A, Choi CH, Zhou Y, and Lindstrom J (2003) Alternate stoichiometries of $\alpha 4 \beta 2$ nicotinic acetylcholine receptors. Mol Pharmacol 63:332-341.

Nielsen BE, Minguez T, Bermudez I, and Bouzat C (2018) Molecular function of the novel $\alpha 7 \beta 2$ nicotinic receptor. Cell Mol Life Sci 75:2457-2471.

Ogunjirin AE, Fortunak JM, Brown LL, Xiao Y, and Dávila-García MI (2015) Competition, selectivity and efficacy of analogs of A-84543 for nicotinic acetylcholine receptors with repositioning of pyridine nitrogen. Neurochem Res 40:2131-2142.

Pabreza LA, Dhawan S, and Kellar KJ (1991) [ $\left.{ }^{3} \mathrm{H}\right]$ cytisine binding to nicotinic cholinergic receptors in brain. Mol Pharmacol 39:9-12.

Papke RL and Thinschmidt JS (1998) The correction of alpha7 nicotinic acetylcholine receptor concentration-response relationships in Xenopus oocytes. Neurosci Lett 256:163-166.

Peng J-H, Lucero L, Fryer J, Herl J, Leonard SS, and Lukas RJ (1999) Inducible, heterologous expression of human $\alpha 7$-nicotinic acetylcholine receptors in a native nicotinic receptor-null human clonal line. Brain Res 825:172-179.

Pettersen EF, Goddard TD, Huang CC, Couch GS, Greenblatt DM, Meng EC, and Ferrin TE (2004) UCSF Chimera--a visualization system for exploratory research and analysis. J Comput Chem 25:1605-1612.

Pitner TP, Edwards WB III, Bassfield RL, and Whidby JF (1978) The solution conformation of nicotine. $\mathrm{A}^{1} \mathrm{H}$ and ${ }^{2} \mathrm{H}$ nuclear magnetic resonance investigation. $J \mathrm{Am}$ Chem Soc 100:246-251.

Potasiewicz A, Golebiowska J, Popik P, and Nikiforuk A (2019) Procognitive effects of varenicline in the animal model of schizophrenia depend on $\alpha 4 \beta 2$ and $\alpha 7 \mathrm{nAChRs}$ nicotinic acetylcholine receptors. J Psychopharmacol 33:62-63.

Prochaska J J and Benowitz N L (2016) The past, present, and future of nicotine addiction therapy. Annual Review of Medicine 67:467-486.

Puskar NL, Xiu X, Lester HA, and Dougherty DA (2011) Two neuronal nicotinic acetylcholine receptors, $\alpha 4 \beta 4$ and $\alpha 7$, show differential agonist binding modes. $J$ Biol Chem 286:14618-14627.

Rouchaud A and Kem WR (2012) Synthesis of racemic 2'substituted nicotines. $J$ Heterocycl Chem 49:161-166.

Rowland NE, Robertson K, Soti F, and Kem WR (2008) Nicotine analog inhibition of nicotine self-administration in rats. Psychopharmacology (Berl) 199:605-613.

Schmidt MW, Baldridge K, Boatz JA, Elbert ST, Gordon MS, Jensen JH, Koseki S, Matsunaga N, Nguyen KA, Su S, et al. (1993) General atomic and molecular electronic structure system. J Comput Chem 14:1347-1363.

Seeman JI (1984) Recent studies in nicotine chemistry. Conformational analysis, chemical reactivity studies and theoretical modeling. Heterocycles 22:165-193.

Sun JL, Stokoe SA, Roberts JP, Sathler MF, Nip KA, Shou J, Ko K, Tsunoda S, and Kim S (2019) Co-activation of selective nicotinic acetylcholine receptors is required to reverse beta amyloid-induced $\mathrm{Ca}^{2+}$ hyperexcitation. Neurobiol Aging 84:166-177.

Tang Y, Zielinski WL, and Bigott HM (1998) Separation of nicotine and nornicotine enantiomers via normal phase HPLC on derivatized cellulose chiral stationary phases. Chirality 10:364-369.

Tavares XDAS, Blum AP, Nakamura DT, Puskar NL, Shanata JA, Lester HA and Dougherty DA (2012) Variations in binding among several agonists at two stoichiometries of the neuronal, $\alpha 4 \beta 2$ nicotinic receptor. J Am Chem Soc 134: 11474-11480.

Testa B and Jenner P (1973) Circular dichroic determination of the preferred conformation of nicotine and related chiral alkaloids in aqueous solution. Mol Pharmacol 9:10-16.

Van Arnam EB, Blythe EE, Lester HA, and Dougherty DA (2013) An unusual pattern of ligand-receptor interactions for the $\alpha 7$ nicotinic acetylcholine receptor, with implications for the binding of varenicline. Mol Pharmacol 84:201-207.

Wang DX, Booth H, Lerner-Marmarosh N, Osdene TS, and Abood LG (1998) Structure-activity relationships for nicotine analogs comparing competition for $\left[{ }^{3} \mathrm{H}\right]$ nicotine binding and psychotropic potency. Drug Dev Res 45:10-16.

Wildeboer K (2005) Structure activity relationships of nicotine analogs and Erythrina alkaloids on the alpha4beta2 nicotinic acetylcholine receptor. Ph.D. thesis, University of Florida, Gainesville, FL.

Wu J and Lukas RJ (2011) Naturally-expressed nicotinic acetylcholine receptor subtypes. Biochem Pharmacol 82:800-807.

Xiu X, Puskar NL, Shanata JAP, Lester HA, and Dougherty DA (2009) Nicotine binding to brain receptors requires a strong cation-pi interaction. Nature 458: $534-537$.

Zhao L, Kuo Y-P, George AA, Peng J-H, Purandare MS, Schroeder KM, Lukas RJ, and Wu J (2003) Functional properties of homomeric, human $\alpha$ 7-nicotinic acetylcholine receptors heterologously expressed in the SH-EP1 human epithelial cell line. J Pharmacol Exp Ther 305:1132-1141.

Zouridakis M, Giastas P, Zarkadas E, Chroni-Tzartou D, Bregestovski P, and Tzartos SJ (2014) Crystal structures of free and antagonist-bound states of human $\alpha 9$ nicotinic receptor extracellular domain. Nat Struct Mol Biol 21:976-980.

Address correspondence to: William R. Kem, Department of Pharmacology and Therapeutics, University of Florida, P.O. Box 100267, Gainesville, FL 32610-0267. E-mail: wrkem@ufl.edu 